Cahiers Charlevoix

Études franco-ontariennes
Cahiers Charlevoix Études franco-ontariennes

or Crevenerix of

\title{
Germain Lemieux par lui-même. Les paradoxes d'un prêtre collecteur
}

\section{Jean-Pierre Pichette}

Volume 11, 2016

URI : https://id.erudit.org/iderudit/1039282ar

DOI : https://doi.org/10.7202/1039282ar

Aller au sommaire du numéro

\section{Éditeur(s)}

Société Charlevoix

Presses de l’Université d'Ottawa

\section{ISSN}

1203-4371 (imprimé)

2371-6878 (numérique)

Découvrir la revue

Citer cet article

Pichette, J.-P. (2016). Germain Lemieux par lui-même. Les paradoxes d'un prêtre collecteur. Cahiers Charlevoix, 11, 13-71.

https://doi.org/10.7202/1039282ar
Résumé de l'article

Le troisième chapitre de " Germain Lemieux par lui-même ", que présente Jean-Pierre Pichette, complète la série autobiographique du célèbre ethnologue (1914-2008) qui a oeuvré en Ontario français durant plus d'un demi-siècle. Tirées de la longue entrevue accordée à l'auteur en 1995, ces ultimes confidences du père Lemieux font suite aux deux volets publiés dans ces pages : un premier chapitre (1914-1958) consacré à son enfance gaspésienne, à sa formation chez les jésuites et à son installation à Sudbury, et un deuxième relatant son parcours universitaire, tardif en ce qui concerne l'ethnologie, et sa carrière de chercheur. Ce volet final rappelle les genres de la littérature orale - conte et chanson - qu'il a privilégiés pour leurs valeurs didactiques ; il témoigne ensuite des convictions qui ont balisé son cheminement pionnier, affichant en outre ses inquiétudes et ses voeux pour l'avenir du legs qu'il a fait à la francophonie ontarienne. L'auteur clôt cette trilogie en épiloguant sur les paradoxes du prêtre collecteur, particulièrement l'ambiguïté et l'originalité de sa posture, mais encore son opiniâtreté et sa marginalité. Les trois volets de ce long entretien exposent le point de vue du jésuite Germain Lemieux, qui fait à rebours le parcours de sa carrière ; ses réflexions sans prétention justifient son action et livrent une perspective inédite.
Ce document est protégé par la loi sur le droit d'auteur. L'utilisation des services d'Érudit (y compris la reproduction) est assujettie à sa politique d'utilisation que vous pouvez consulter en ligne.

https://apropos.erudit.org/fr/usagers/politique-dutilisation/ 


\title{
Germain Lemieux par lui-même. Les paradoxes d'un prêtre collecteur
}

\author{
JeAn-Pierre Pichette
}

Chaire de recherche du Canada en oralité des francophonies minoritaires d'Amérique (COFRAM) Université Sainte-Anne, Pointe-de-l'Église 


\section{SOMMAIRE}

AvANT-PROPOS

XII - De LA ChANSON : PRopos ET CRITIQUeS

XIII - LE CONTE : TRADITION ORALE ET COMPOSITION

XIV - L'IMPACT ARTISTIQUE ET SCIENTIFIQUE

XV - UN FOLKLORE FRANCO-ONTARIEN 45

XVI - Du collège du Sacré-Ceeur À l’Université... FRANCO-ONTARIENNE

ÉPILOGUE : LeS PARAdOXES D'UN PRÊTRE COLLECTEUR

1. Origines paysannes et formation classique 56

2. Le pédagogue : le folklore au secours des humanités 58

3. Études universitaires d'un autodidacte

4. Un missionnaire aux visées nationalistes 


\section{Germain Lemieux par lui-même. Les paradoxes d'un prêtre collecteur}

\section{Avant-Propos}

En 1995, dans le cadre d'une série radiophonique, Germain Lemieux nous accordait une dizaine d'entretiens sur sa carrière d'ethnologue en Ontario français. Véritable bilan d'une activité incomparable, son témoignage, livré avec simplicité et retenue sur le ton de la confidence, requérait un traitement actualisé, car il éclaire les dessous de l'œuvre en exposant une face cachée du personnage. C'est avec le dessein de pérenniser la portée des documents diffusés à cette époque, il y a maintenant plus de deux décennies, que nous avons conçu le projet d'éditer la substance de ses propos dans cette suite autobiographique de « Germain Lemieux par lui-même ».

Notre interlocuteur connaissait bien le contexte de l'entrevue dont le scénario, conçu expressément à partir de son œuvre, avec citations à l'appui, lui avait été communiqué. Germain Lemieux en avait pris connaissance et savait à l'avance sur quoi portait chacune des séances. Il s'y était préparé en conséquence. Pour la partie publique du personnage, c'est-à-dire celle diffusée par son œuvre écrite, il a suffi de lui faire raconter et préciser sa perspective, ses mobiles, ses projets et leur réalisation avec leur impact connu. Pour la partie intime - sa famille biologique, son enfance et son cheminement scolaire jusqu'à son entrée chez les jésuites et son affectation à Sudbury -, chapitre sur lequel il s'était toujours montré discret, nous avons préféré attendre les dernières séances, après le récit de sa carrière, afin qu'il se sentît en confiance pour l'aborder. L'ultime entretien a porté sur sa vision de l'Ontario français. 
Pour l'édition de ces entretiens, l'ordre chronologique s'est imposé. Le premier chapitre, qui couvrait l'enfance et la formation de ce Gaspésien jusqu'aux premières années d'enquête sur le terrain et d'enseignement à Sudbury, s'étendait de 1914 à 1958 ${ }^{1}$. Le deuxième évoquait ses études à l'Université Laval à compter de 1952, la confrontation d'un savoir-faire acquis par la pratique à celui de professionnels, ses maîtres, et sa carrière d'universitaire et de chercheur jusqu'aux années de retraite ${ }^{2}$. Ce troisième et dernier chapitre, affranchi d'une datation précise, s'attache à certaines de ses réflexions sur la chanson et le conte populaires, genres qui l'ont particulièrement fasciné et dont il a cherché à illustrer les vertus pédagogiques ; il affiche aussi ses convictions sur l'existence d'un folklore franco-ontarien et il livre, en guise de testament, ses craintes et ses espoirs pour l'avenir de sa documentation dans une institution qu'il appelle de tous ses vœux : l'université franco-ontarienne.

En épilogue, nous reprenons en quelques grands traits les principales impressions qui émergent de ces longs entretiens. Elles mettent en évidence l'ambiguïté de la posture de ce prêtre original qui opta pour les traditions populaires. Son choix, radicalement opposé à la formation dispensée par les collèges classiques et discrédité par l'élitiste compagnie de Jésus, se réalisa néanmoins avec toute la ferveur d'une vocation au sein des institutions de cet ordre, mais à l'écart des courants disciplinaires. Opiniâtre et marginal, souvent nourri par la contrariété, il parvint à accomplir une œuvre insigne dont les prolongements sont multiples.

1. Jean-Pierre Pichette, "Germain Lemieux par lui-même (1914-1958) ", Cahiers Charlevoix 9. Études franco-ontariennes, Ottawa, Société Charlevoix et Presses de l'Université d'Ottawa, 2012, p. 107-193.

2. Id., « Germain Lemieux par lui-même (1952-1995) », Cahiers Charlevoix 10. Études franco-ontariennes, Ottawa, Société Charlevoix et Presses de l'Université d'Ottawa, 2014, p. 65-169. 


\section{XII - De la Chanson : PROpos et CRITIQues}

"De la chanson qui tourne autour des réalités canadiennes" Quand j'étais à [1'Université] Laval, on avait posé la question à monsieur Marius Barbeau ${ }^{3}$ : « Quand est-ce qu'il parlerait de la chanson authentiquement canadienne? » Celui qui avait posé la question savait probablement de quoi il s'agissait. Il s'agissait surtout de la chanson qui tourne autour des réalités canadiennes. Par exemple les chantiers ${ }^{4}$, ce ne sont pas les Français qui les ont inventés; la cabane à sucre par exemple, ce qui regarde le sucre d'érable, ça c'étaient les Indiens et ensuite le Canada [français] $]^{5}$. Là où les Français ne connaissaient à peu près rien, sous le Régime français, on peut dire que c'est d'invention canadienne-française.

\section{"Une adaptation de chansons françaises"}

Il y a une autre catégorie de chansons qui est canadienne, mais qui a été une adaptation de chansons françaises. Je parlais l'autre jour des Trois beaux canards ${ }^{6}$ qui ont été mêlés à plusieurs sauces : des chansons de marche, des chansons qui accompagnaient les coups de marteau, des chansons qui accompagnaient le coup d'aviron, le coup de rame. On a conservé souvent la courbe musicale française, mais on a changé le rythme et puis on a adapté des [refrains] comme « Le canot d'écorce qui vire, qui vole, / Le

3. Marius Barbeau (Sainte-Marie-de-Beauce, Qc, 1883-Ottawa, Ont., 1969), anthropologue et folkloriste qui fit carrière au Musée national d'Ottawa de 1911 à 1948. Il fut professeur à l’Université Laval de 1945 à 1954.

4. Les premiers chantiers forestiers sont apparus à la fin du XVIII ${ }^{\mathrm{e}}$ siècle sous le Régime anglais ; ils se sont généralisés au XIX et ont subsisté jusque dans la seconde moitié $\mathrm{du} \mathrm{Xx}^{\mathrm{e}}$ siècle. Ce sont des établissements d'hiver destinés à la coupe et au transport du bois où vivaient les bûcherons et charretiers jusqu'au printemps.

5. Les Amérindiens savaient « recueillir la sève d'érable qu'ils faisaient bouillir en y mettant des cailloux rougis dans un brasier », comme l'explique Marius Barbeau, "Le Temps des sucres », Cahiers de l'Académie canadienne-française, vol. 9, Folklore, Montréal, [s.d., v. 1965] ; voir aussi Michel Lambert, Histoire de la cuisine familiale du Québec, vol. 1, Ses origines autochtones et européennes de la préhistoire au XIX siècle, Québec, Les Éditions GID, 2006, p. 321-322 ; mais ce sont les Canadiens français qui ont développé la cabane à sucre au cours du XIX siècle.

6. Les Trois beaux canards, Laforte I-B-7. Voir Conrad Laforte, Le Catalogue de la chanson folklorique française, Nouvelle édition augmentée et entièrement refondue, Québec, Presses de l'Université Laval, 1977-1983, 6 vol. [désormais Laforte]. 
canot d'écorce qui vole au vent ». Ça, les Français n'avaient pas vu ça. Ce sont probablement des coureurs de bois ou des gens qui partaient pour des années, des mois, chercher des fourrures, qui adaptaient ces chansons-là. Nous en avons beaucoup de ces chansons-là : j'ai mentionné Les Beaux Canards, il y avait Le Petit Mari ${ }^{7}$ qui existe encore en France, mais qui a été remaniée ici au Canada en ajoutant un refrain, en changeant encore le rythme ou parfois la mélodie ; les chansons de voyageurs, surtout les voyageurs dans l'Ouest ou les gens qu'on appelait le « voyageur canadien » qui était ni plus ni moins qu'un bûcheron qui allait de camp en camp pour gagner sa vie. Dans nos chansons canadiennes, souvent le voyageur a pris ce sens-là d'un bonhomme qui voyage d'un chantier à l'autre. Tout ça, c'est dans la chanson canadienne.

\section{"Les complaintes de noyades sur le Saint-Laurent"}

D'autres adaptations : il y a les complaintes, les complaintes de noyades sur le Saint-Laurent ou dans des rivières ; ça regarde le Canada et ç'a été fait par des Canadiens, des gens qui ont assisté à ces catastrophes-là ou bien qui en ont entendu parler. Encore une fois, on se servait des thèmes folkloriques français, des chansons françaises, pour recomposer les chansons, soit des complaintes ou d'autres chansons. Par exemple Isabeau s'y promène $e^{8}$ qu'on a adaptée à plusieurs rythmes, suivant qu'on voulait faire une chanson de rame, une chanson d'aviron, une chanson de danse ; il y avait toujours quelque chose de changé au Canada, mais c'était une adaptation. Dans la chanson authentiquement canadienne, Marius Barbeau a trouvé des mélodies qui ont probablement été composées et qui sont greffées sur le grégorien : très souvent c'est un mode grégorien qui a servi à cette chanson authentiquement canadienne. C'est assez rare quand même. Je ne me rappelle pas d'avoir recueilli moi-même des chansons où le chanteur avait composé sa propre chanson ; c'était une modulation plutôt, c'était une adaptation d'une autre mélodie.

7. Le Petit Mari, Laforte I-D-9.

8. Le titre du catalogue Laforte est différent : L'Embarquement de la fille aux chansons et le plongeur noyé, Laforte I- B-11. 


\section{"Cette coïncidence entre l'accent musical et l'accent de la}

\section{langue "}

L'isorythmie. Cherchez ce mot dans le dictionnaire, même le grand dictionnaire Larousse. Je l'ai cherché moi-même et je ne

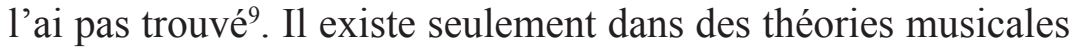
qui remontent à quelque cinquante ans, soixante ans. J'avais été intéressé comme d'autres, ce qui me faisait rire, [au cantique] Esprit saint, descendez en nous. Et je me demandais ce que c'était le saint dé ; ce qu'on entend, c'est « Esprit saint dé, sans dés en nous ». Scindé veut dire brisé, disloqué. Pourquoi ? Parce que les accents ont été mal placés. L'isorythmie, c'est cette coïncidence entre l'accent musical et l'accent de la langue, des vers. Vous savez que les vers sont rythmés et, quand on met ça en musique, il faut que l'accent musical coïncide avec l'accent rythmique des paroles. C'est ça qui m'a intéressé, moi, à étudier l'isorythmie et à surveiller les chansons françaises.

\section{"Ô Canada, ter-reur de nos ä̈eux"}

Je me rappelle qu'en 1939-1940 il y avait une commission à Montréal qui avait été mise en place pour refaire le $\hat{O}$ Canada $^{10}$. Il y avait énormément de manque d'isorythmie dans le $\hat{O}$ Canada. J'en ai eu connaissance parce qu'un jésuite venait d'arriver de l'Europe avec un doctorat en musique, et puis il faisait partie de cette commission-là. Je ne sais pas si cette commission a travaillé beaucoup, mais on chante encore « terreur de nos aïeux ». Il y a

9. On le retrouve aujourd'hui dans le Dictionnaire de la musique en ligne Larousse, mais au sens de procédé musical qui consiste en la répétition " d'un même schéma rythmique »; la relation entre les paroles et la musique en est absente. Source : www.larousse.fr/archives/rechercher?q=isorythmie\&base=musique (consultée le 20 août 2015).

10. Hymne composé pour la Saint-Jean-Baptiste en 1880 par Calixa Lavallée (1842-1891) sur un poème d'Adolphe-Basile Routhier (1839-1920). L'article de l'Encyclopédie canadienne rétablit les circonstances de la création de cet hymne, en évoque les étapes qui en firent l'hymne national des Canadiens français puis du Canada avec les traductions anglaises et les vaines tentatives pour le rendre inclusif à l'endroit des immigrants et des femmes. Source : www.encyclopediecanadienne. ca/fr/article/o-canada (consultée le 2 octobre 2015). Mais il n'a pas été possible de trouver trace de cette commission chargée de réviser les paroles françaises de l'hymne national. 
des gens qui sont surpris, mais c'est bien vrai. Parce que l'accent du Ô Canada, c'est « Ô Canada, ter-re de nos aïeux », on entend « ter-reur de nos aïeux ». À la fin du couplet - [Et répétons comme nos pères] « Le cri vainqueur : "Pour le Christ et le Roi" »-, il y a un petit gars qui a demandé : «Qui c'est qu'est monsieur Incristé ? » Pourquoi ? Parce qu'il a mal compris, l'accent est mal placé. Prenez Ô Canada, mettez «pays de nos aïeux »-il y a une nuance dans le sens -, mais on comprend. Tandis que si on chante ter-re, l'accent était mal placé, c'est le même accent que ter-reur. C'est pour ça que j'attribue énormément d'importance à l'isorythmie dans nos chansons, les chansons anciennes comme les chansons actuelles.

\section{"C'est le truc des chansons à répons"}

Ça, c'est le truc des chansons à répons. Vous ne pouvez pas répondre à une chanson, si vous ne la comprenez pas. Pour la comprendre, il faut que les accents soient au bon endroit. J'ai fait chanter une chanson, Mes souliers sont rouges ${ }^{11}$, à des élèves. Il y a peut-être douze couplets, je ne les ai pas comptés, et on comprend tous les accents. C'est un bonhomme qui habille son monsieur des pieds à la tête, en partant de ses souliers jusqu'au chapeau. Et je n'ai pas trouvé une seule faute contre l'isorythmie là-dedans. Il y a des abréviations, mais c'est tellement bien rythmé qu'on la comprend, on est capable de répéter ces chansons-là. Les gens [de l'assistance], au-delà de 350 personnes, ils ont répondu du commencement à la fin parce qu'ils comprenaient la chanson. Et c'est pour ça que, pour moi, c'est excessivement intéressant et c'est primordial dans une chanson. J'en ai conclu, avec plusieurs autres exemples, que nos analphabètes avaient le sens de l'isorythmie.

\section{"C'est dans l'esprit français de comprendre une chanson"}

Je me rappelle de certains cantiques qui étaient mal rythmés au collège, et les étudiants, après avoir été laissés à eux-mêmes,

11. Si j'avais les beaux souliers, Laforte IV-Eb-2. 
reprenaient le rythme véritable de la poésie. Je me suis dit : «Ce n'est pas une invention ça, c'est dans l'esprit français de comprendre une chanson ». Surtout nous sommes forts, nous autres, sur les chansons à répons pour que nos gens répondent à une chanson comme je l'ai fait faire avec Mes souliers sont rouges. Je reviens avec ça, l'importance de l'isorythmie, de cette coïncidence de l'accent poétique avec l'accent musical, pour qu'on comprenne, parce que la chanson, en général, elle porte un message. Si on ne comprend pas les paroles, on ne comprend pas le message. Alors à quoi bon composer une chanson qui n'est pas comprise, que les gens n'entendent pas et ne peuvent pas répéter?

\section{"La Bolduc va faire son chemin"}

Et pour moi, j'avais été critiqué autrefois. Je trouvais que la Bolduc $^{12}$ allait faire son chemin. On disait : « Elle ne sait pas son français, elle n'a pas d'éducation... » J'ai dit : « La Bolduc va faire son chemin parce que des gens répètent ses chansons, comprennent ses chansons ». Je n'ai pas fait l'analyse de toutes ses chansons, mais c'est impeccable comme isorythmie.

Mon vieux est jaloux / ah oui, je le sais bien Il dit que j' m'occupe / du gars du voisin ${ }^{13}$

C'est presque parfait comme isorythmie et ça, ça tombe dans l'oreille de l'auditeur. Moi, j'ai appris bien des chansons de la Bolduc sur les disques simplement à l'écouter parce qu'on comprenait. Si les chansonniers actuels veulent que leurs chansons soient chantées dans vingt-cinq ans, dans cent ans, il faudrait qu'ils

12. La Bolduc ou Madame Bolduc, pseudonyme de Mary Travers (Newport, Québec, 1894-Montréal, 1941), auteur-compositeur-interprète, est une musicienne autodidacte qui s'inspira de la tradition orale. Elle connut un vif succès en racontant la vie quotidienne de son temps. Ses chansons, endisquées entre 1929 et 1939, sont encore très connues. On a écrit plusieurs ouvrages sur elle, dont ceux-ci : Réal Benoît, La Bolduc, Montréal, Éditions de l'Homme, 1959, 123 p. ; David Lonergan, La Bolduc: la vie de Mary Travers (1894-1941) Biographie, Bic (Québec), Isaac-Dion éditeur, 1992, 212 p. ; Pierre Day, Une histoire de La Bolduc : légendes et turlutes, Montréal, VLB éditeur, 1991, 130 p. ; Lina Remon et Jean-Pierre Joyal, Madame Bolduc : paroles et musiques, Montréal, Guérin éditeur, 1993, 245 p.

13. Lina Remon et Jean-Pierre Joyal, op. cit., p. 78-79: 23. Mon vieux est jaloux, paroles et musique, chanson enregistrée le 18 juin 1930. 
fassent une étude plus attentive sur l'isorythmie, qu'ils donnent un texte qui soit intelligible et que les gens comprennent, qu'ils puissent répéter.

\section{"C'est tombé tout de suite dans l'oreille des gens"}

Notre ami Gilles Vigneault a fait chanter des chants par une foule à Montréal. Extraordinaire ! Gens du pays... qu'on chante à des gens qui fêtent leur anniversaire ${ }^{14} .$. C'est tombé tout de suite dans l'oreille des gens. Pourquoi ? Parce que c'est bien rythmé. Ses chansons en général, à Vigneault, c'était presque parfait au point de vue d'isorythmie. Ça tombe dans l'oreille et les gens ont du plaisir à chanter ça. Parfois il y a une syllabe qu'ils ne comprendront pas puis qu'ils vont changer, mais justement ils changent la syllabe parce qu'ils ne la comprennent pas ; mais, dès qu'ils comprennent la syllabe, ils vont la répéter telle quelle. C'est mon cheval de bataille ça, dans la musique ou dans la chanson, dans l'enseignement. Les gens rient de moi. Au début, ils ont commencé à me montrer le poing parce que je parlais de «terreur de nos aïeux » et ils disaient que c'était pas catholique de rire du Ô Canada comme ça. J'ai dit non, faudrait le réformer. Et moi, j'aurais un souhait à faire après cette petite causerie-là : il faudrait qu'une université ou un collège ou une institution quelconque institue un cours d'isorythmie de la chanson.

\section{"Au point de vue isorythmique, c'était nul et sacrilège "}

Quelqu'un a donné déjà, dans une certaine université, un cours sur la chanson. Je lui ai demandé s'il avait insisté sur l'isorythmie. Il ne savait même pas ce que c'est que l'isorythmie. J'ai dit : «Comment pouviez-vous juger une chanson ? » Il dit : « Je jugeais simplement sur l'engagement politique ». De sorte qu'une chanson qui gueulait contre les Canadiens français ou qui gueulait

14. Gilles Vigneault (Natashquan, 1928), auteur-compositeur-interprète, poète et conteur, a composé la chanson Gens du pays pour la fête nationale du Québec le 24 juin 1975. On la considère depuis comme l’hymne national du Québec et on chante son refrain à l'occasion des anniversaires de naissance. Pour le texte de Gens du pays, voir Gilles Vigneault, Les Écrits - Chansons I, Édition établie et présentée par Gabriel Landry, Montréal, Éditions du Boréal, 2013, p. 401-402. 
contre les Anglais, ça c'était une bonne chanson ; alors qu'au point de vue rythmique, au point de vue musical, au point de vue isorythmique, c'était nul et sacrilège. Alors, je me suis aperçu que ça prendrait quelqu'un de sérieux, qui soit au courant à la fois du rythme de la poésie et de la musique, pour alimenter un cours qui serait fréquenté, je l'espère, par bien des élèves, et qui mettrait en garde contre les fautes abominables qu'on fait dans les annonces publicitaires par exemple. Il y a dix ans, quelqu'un à Ottawa qui vendait des poulets au restaurant [annonçait] : « On vous sert des poulets comme vous... l'aimez ». Il y a assez de personnes qui ont protesté : « des poulets comme vous ». Il y a énormément d'annonces publicitaires comme ça qui sont abominables pour le français : on déplace l'accent ; naturellement il n'y a pas seulement l'isorythmie, mais aussi le français, et, dans la chanson, surtout chez les jeunes.

\section{XIII - LE CONTE : TRADITION ORALE ET COMPOSITION}

\section{"Tous les contes que j’ai publiés me plaisent"}

Les pièces dont je suis le plus fier, ce seraient plutôt les contes. Tous les contes que j'ai publiés me plaisent autant 1'un que l'autre, même si ce sont des contes de deux heures, des contes de dix minutes ou des légendes de trois minutes ; ça me plaisait énormément. Je ne pourrais pas vous dire une préférence, quoiqu'il $\mathrm{y}$ ait certains contes qui sont très bien racontés et qui me plaisent davantage ; quant à la qualité même du conte, le contenu, pour moi, c'est tout égal. Quand il y avait des gars qui me racontaient les épisodes d'Hérodote ${ }^{15}$ ou de Gilgamesh, trois mille ans avant Notre Seigneur, ça me faisait plaisir. Je savais d'où venaient les contes d'Hérodote : de l'Égypte ; et que l'Égyptien très souvent nous racontait des vieilles chansons de l'Assyro-Babylonie, de la Mésopotamie. Le lien que je faisais avec mes lectures, avec mes études de l'Antiquité, ça me faisait plaisir.

15. Hérodote, historien grec du $\mathrm{V}^{\mathrm{e}}$ siècle av. J.-C. 


\section{"Le conteur de Sudbury n'a pas inventé ça"}

J'ai recueilli une version de Cric et Croc (fins voleurs) dans la région de Sudbury ${ }^{16}$. Dans certaines versions, les deux fins voleurs avaient négligé de mettre du ciment autour d'une brique puis ils rentraient par là pour aller voler l'or du roi. Mais, à Sudbury, c'est une autre version. Les deux voleurs se sont ingéniés à creuser un tunnel; ils sont partis de la cave d'un fin voleur, ils ont creusé un tunnel en direction de la banque du roi. Ils connaissaient assez leurs mathématiques et leur trigonométrie pour orienter leur tunnel en dessous de la banque du roi. Et, quand ils ont été rendus en dessous, ils ont percé un trou, et puis l'or et l'argent leur tombaient sur la tête. Ça, c'était quelque chose qui était très ancien. Et je me disais : «Le conteur de Sudbury n'a pas inventé ça ». Il n'a pas pu inventer ça, de même que les autres conteurs du Québec, de l'Ontario, qui avaient toujours le même truc d'aller s'engager pour bâtir la banque du roi avec des pierres ou des briques : ils laissaient une certaine entrée sans mettre de ciment, puis ils allaient tirer la pierre ou les briques et ils entraient par là. C'était ma seule version de gens qui creusent un tunnel et qui volent la banque du roi par en dessous. J'avais trouvé ça extraordinaire de voir que ce vieux bonhomme qui ne savait ni lire ni écrire - du moins je crois qu'il ne savait ni lire ni écrire -, qui n'avait pas pu étudier le grec, qui n'avait pas pu lire les histoires d'Hérodote ${ }^{17}$

16. Version d'Alphonse Brault, soixante-dix-sept ans, recueillie à Sudbury en mars 1965, publiée dans Les vieux m'ont conté [désormais LVMOC], Montréal, Bellarmin, et Paris, Maisonneuve et Larose, vol. 2, 1974, p. 79-91 : Cric et Croc (fins voleurs), conte type ATU 950 Rhampsinite de la troisième révision du catalogue international publié sous la direction de Hans-Jörg Uther, The Types of International Folktales, A Classification and Bibliography Based on the System of Antti Aarne and Stith Thompson, Helsinki, Suomalainen Tiedeakatemia, "FFC » 284, 285, 286, 2004, 3 vol. [désormais Aтu]. Voir aussi la note sur ce conteur dans Les Jongleurs $d u$ billochet : conteurs et contes franco-ontariens, Sudbury, Shno, « Documents historiques » 61-62-63, Paris, Maisonneuve et Larose, et Montréal, Bellarmin, 1972, p. 85-90.

17. Hérodote, Histoires, Livre II Euterpe, chap. CXxI. Voir Histoire d'Hérodote traduite du grec par M. [Pierre-Henri] Larcher, Paris, chez Musier [et] Nyon, 1786, tome second, p. 95-100; voir ce passage aux p. 95-96: " Pour mettre ces richesses en sûreté, il [Rhampsinite] fit élever un édifice en pierres, dont un des murs étoit hors de l'enceinte du palais. L'architecte, qui avoit de mauvais desseins, arrangea une des pierres avec tant d'art, que deux hommes, ou même un seul, pouvoient facilement l'ôter. » 
- moi, j'étais au courant de ça par des traductions, au collège, du grec au français -, il n'a pas pu l'apprendre autrement que par la tradition orale. Pour moi, c'est toujours cette force de la tradition orale qui me frappe toujours.

\section{"Son bateau, c'est notre bâtiment merveilleux"}

Dans les contes merveilleux, il s'agit de sorcières, de géants, de métamorphoses, un peu de toutes sortes de choses comme ça, du merveilleux quoi. Il y a des personnages qui ont survécu. Par exemple, j'avais dit à mes élèves d'où venait le mot roi : de rex, regis, naturellement du latin ; mais le rex vient de regere qui veut dire gérer, gérer quelque chose, être à la tête d'une entreprise. Le roi, autrefois, c'était surtout un bonhomme qui conduisait la guerre, il était toujours prêt, puis on voit dans l'Iliade ${ }^{18}$ qu'il y avait un roi qui était assez puissant puis il était intelligent. On va le voir et on dit : " Écoute un peu, il faut aller contre la ville de Troie et puis on aurait besoin d'un roi, d'un chef »- au fond, le roi à ce moment-là c'était un chef. Il est allé à la guerre, il a conduit la guerre contre Troie et puis les Grecs ont remporté la guerre. Dans nos contes très souvent, le roi, c'est un peu ça; ce n'est pas un roi qui a une couronne sur la tête et qui a des bagues en diamant et en or, c'est un bonhomme qui conduit les autres. En fait, il est assez rustaud, mais seulement on a confiance dans le roi pour conduire la guerre et pour les expéditions comme ça. Je vois dans l'Iliade et l'Odyssée la fameuse conquête de la toison d'or. Jason, qui conduisait la quête de la toison d'or, part en bateau ${ }^{19}$. Et imaginez-vous que son bateau, c'est notre bâtiment merveilleux parce que, à bord de ce bâtiment-là, vous avez Hercule, vous avez lui, Jason, puis vous avez des géants ou des gens qui sont très forts, très intelligents, et ils partent à la conquête de la toison

18. Euvre d'Homère, du IX ${ }^{\mathrm{e}}$ siècle av. J.-C.

19. Il y a bien une seule et très brève allusion à Jason au chant XII de l'Odyssée : « Le navire Argo, célébré par tous les chanteurs, fut le seul qui, en revenant des contrées d'Aétès, franchit ce passage ; il se serait même brisé contre ces rochers s'il n'eût été conduit par la belle Junon, car Jason était cher à cette déesse. » La référence pour cette épopée, Les Argonautiques, est plus tardive et elle est l'œuvre d'Apollonios de Rhodes (v. 295-v. 215 av. J.-C.). 
d'or ${ }^{20}$. Je n'irai pas jusqu'au bout de cette toison d'or-là, mais finalement il la rapporte : c'était une richesse extraordinaire. Ce sont des personnages comme ça : Hercule, c'est Ti-Jean Poilu qui prend son père puis qui le casse en deux... ${ }^{21}$ On sait qu'Hercule s'est choqué. Son père voulait lui faire apprendre la musique ; je pense bien qu'Hercule n'était pas très très musicien, il n'avait pas la patience de suivre toutes les leçons de solfège et les leçons d'harmonie. À un moment donné, son professeur lui a dit : « Tu n'avances à rien, tu n'as pas d'oreille ». Il prend son instrument et le casse sur la tête du professeur et puis ça arrive comme ça. Alors Ti-Jean Poilu, la même chose, il maltraite son père, sa mère au risque de les tuer. C'est absolument les mêmes scènes que l'on retrouve chez les rois anciens parce que souvent Ti-Jean a été roi, lui aussi, à sa façon. Ti-Jean Poilu en a conduit du monde et puis on peut dire qu'il aurait eu le talent d'être roi.

\section{"Ce sont les tours de Ti-Jean"}

Ce qu'on retrouve le plus abondamment dans notre folklore, je crois bien que ce sont les tours de Ti-Jean ${ }^{22}$ : les tours de Ti-Jean à son roi ou à son seigneur. Dans l'Ouest, à Saint-Boniface, j'avais pris un conte de Ti-Jean et c'était un tour que je n'avais pas encore enregistré ici dans l'Ontario et dans le Québec.

C'est le roi qui est à la porte de son foyer et qui attend Ti-Jean. Ti-Jean y va tous les jours, puis il lui propose telle chose et lui joue des tours. Alors le roi s'est dit: « Je vais lui en jouer un, moi aussi ». Il occupe Ti-Jean près du foyer à jaser puis

20. Il s'agit du type Atu 513 Le Bateau qui va sur terre comme sur mer ou Les Doués (Delarue-Tenèze) dont Germain Lemieux a recueilli huit versions intitulées, entre autres, Le Bâtiment merveilleux ou Le Bâtiment qui va sur terre, sur mer et dans les airs.

21. Le héros du type Atu 301 Jean de l'Ours (Delarue-Tenèze) est aussi un homme doté d'une force herculéenne nommé Jean Poilu, Jean de l'Ours, Gros Jean, Poil et Plume, etc. ; on en dénombre dix-huit versions dans la collection Lemieux. Ce héros est encore présent dans le type Aтu 650 Jean le Fort ou Quatorze (DelarueTenèze) ; il porte souvent le même nom dans les neuf versions Lemieux avec en plus son célèbre Barbaro-les-Grandes-Oreilles.

22. Pas moins de vingt-huit versions de sa collection portent en titre « joueur de tours ", le plus souvent associé à Ti-Jean, non plus l'homme fort, mais sous son avatar de personnage astucieux qui trompe le roi (cycle 1525-1639). 
il dit à ses serviteurs : " Allez couper la queue du cheval de Ti-Jean ». Les serviteurs ont coupé la queue du cheval de Ti-Jean. Ti-Jean sort du château du roi puis il voit son cheval, la queue coupée, puis il saigne : il ne dit pas un mot. Il embarque dans sa voiture, passe près des écuries du roi et puis là il voit ses chevaux. Il entre dans l'écurie du roi ; il y avait de beaux chevaux de selle. Il prend un couteau puis taille les bajoues des chevaux, les chevaux saignent... Puis il s'en va chez lui. Les palefreniers viennent voir le roi le soir puis ils ont dit : « Vos chevaux sont tous massacrés, ça doit être Ti-Jean qui a massacré ces chevaux-là. Ça n'a pas de bon sens, toutes les joues sont coupées et les chevaux ont saigné abondamment $»$. Le roi fait demander Ti-Jean tout de suite. Ti-Jean vient, et avec son front ordinaire, il paraît devant le roi. Puis le roi dit : «C'est toi qui as coupé les joues ?... - Moi ? Massacrer vos chevaux ? Voyons donc, sire le roi, je vous respecte plus que ça puis je vous aime plus que ça. C'est quelque chose d'extraordinaire ça, de massacrer des beaux chevaux comme ça, des chevaux de selle. - C'est arrivé le même jour... - Ah, il dit, je sais, je vais vous donner la raison. Vous savez, quand je suis parti l'autre jour, j'ai coupé la queue de mon cheval puis je suis passé près de vos écuries ; puis je me rappelle très bien que les chevaux me regardaient passer par la fenêtre et ils ont ri tellement qu'ils se sont fendu les bajoues et c'est de votre faute $\gg{ }^{23}$

Les autres thèmes qui reviennent souvent, en plus des tours de Ti-Jean, c'est la question des princesses qui étaient à moitié sorcières. On en a abondamment des petites femmes, des petites princesses, des petites filles qui trahissent leur père. Elles disent à Ti-Jean : «Fais-toi-s'en pas, mon père va faire ci puis c'est ça qu'il va te demander; je vais te dire comment t'y prendre et puis n'aie pas peur, tu vas voir ${ }^{24} \gg$. Je ne dirais pas que ce sont les thèmes les plus fréquents - les tours de Ti-Jean et puis les

23. D'après la version de Joseph Villebrun, quatre-vingt-sept ans, recueillie à Saint-Boniface en 1971 : «Raquelore (Tours au roi) ", dans LVMOC, vol. 6, p. 335340. Classé sous un type inexistant (1345*), ce récit relève du cycle ATU 1525-1639 L'Homme ingénieux, motif J1169.5, «L'Âne qui rit ».

24. C'est le thème du type Atu 313, La Fuite magique ou La Fille du diable (Delarue-Tenèze), dont la collection Lemieux compte treize versions. L'héroïne aux pouvoirs surnaturels, qui assiste le héros dans des tâches impossibles, s'appelle souvent la Belle Jarretière verte. 
indiscrétions des sorcières, parfois des épouses qui trahissent les secrets de leur mari -, mais ce sont des thèmes qui arrivent très souvent dans nos contes.

\section{"Ils mettaient ça bout à bout"}

Des tours comme ça, dans l'Ancien Régime, soit du Moyen Âge ou de l'Antiquité, on en rencontre et puis ç'a été retransplanté dans notre littérature orale en abondance. Plusieurs conteurs m'ont dit ça, dans les chantiers surtout : [il] fallait qu'ils allongent leur conte pour avoir deux heures de conte le samedi soir. Il y avait un commun dénominateur. Les tours que Ti-Jean avait joués à son seigneur ou au roi, ils mettaient ça bout à bout et puis ça rallongeait le conte d'une bonne demi-heure ; c'est comme ça qu'ils ne se faisaient pas trop matraquer ${ }^{25}$ par les gens de chantier.

\section{"Mais nos contes, c'est plutôt de la composition"}

Plusieurs m'ont demandé : « Est-ce que vos conteurs n'inventent pas le conte ? \Je ferais une différence entre inventer puis composer. Pour moi, inventer, c'est un peu une création comme le bon Dieu qui a fait quelque chose avec rien. On dit d'un artiste qu'il va inventer, ou d'un technicien, qui est très intelligent, qu'il va inventer une autre technique ; ça, c'est de l'invention. Mais nos contes, c'est plutôt de la composition : composer, ça veut dire componere, mettre ensemble des éléments qu'on a déjà appris par ailleurs. Le conteur, il en a entendu conter de toutes sortes et puis il peut mettre ensemble des éléments qu'il a colligés à droite puis à gauche chez les autres conteurs. Je me rappelle de mon vieux conteur gaspésien qui contait dans les chantiers ${ }^{26}$. Il s'était aperçu que les jobbeurs ${ }^{27}$ l'engageaient - ils étaient toujours trois, quatre

25. Exagération pour chicaner.

26. Antoine Landry (Cap-Chat, 1871-196?) dont une tranche de vingt-sept contes a été publiée dans $L V M O C$, vol. 22-24. Ses deux fils, qui tenaient leur répertoire de leur père - qu'ils estimaient à plus de 250 contes - en ont livré dix-huit de plus : Gérard Landry (Cap-Chat, 1913-1988), seize, et son frère Paul-Émile Landry (Cap-Chat, 1901), deux autres, aussi parus dans LVMOC, vol. 24-27.

27. Jobbeur (prononcé djobeur), de l'anglais jobber, entrepreneur, contracteur forestier. Voir Gaston Dulong et Gaston Bergeron, Le Parler populaire du Québec 
entrepreneurs qui couraient après lui - pour aller conter dans les chantiers, et que les bûcherons, souvent les mêmes bûcherons, le suivaient parce qu'il était bon conteur et puis on ne voulait pas s'ennuyer la soirée du samedi ou dimanche. Le monsieur m'a dit : «Il faut que je change mes contes ». Tout de suite, il dit : «Tiens, il y a des conteurs à bord des goélettes, je vais m'engager sur une goélette ». En sortant du chantier au mois d'avril, il s'en venait sur une goélette. Naturellement, à bord de la goélette, tout se faisait à la voile - ce dont il me parlait se passait vers les 1878, 1880, 1882, tous les bateaux fonctionnaient à la voile. Il dit : "Quand on avait mis les voiles au vent puis que tout était réglé, je m'assoyais sur un petit quart à clous ${ }^{28}$ sur le pont du bateau puis je contais les contes que j'avais contés dans les chantiers ». Les gens qui étaient allés dans les chantiers ne travaillaient pas à bord du voilier. Il arrivait à Québec, [dans] le bassin Louise. Tous les bateaux, les voiliers qui viennent de la Gaspésie, qui viennent du lac Saint-Pierre, qui viennent des Îles-de-la-Madeleine, qui viennent de Terre-Neuve, allaient là pour charger ou décharger la marchandise. Le conteur était là puis il suivait l'équipage. Comme le capitaine a dit : «J'ai un bon conteur, il nous a conté des contes tout le long du voyage, de la Gaspésie jusqu'à Québec, je vous invite ce soir, les amis, l'équipage de trois, quatre bateaux, venez écouter le conte de mon conteur $»$. Les gens arrivaient à six heures et demie, sept heures, parce que, à ce moment-là, surtout en automne, il m'a fait remarquer : " On n'avait pas de lumière électrique, on s'éclairait seulement avec des fanaux à l'huile et, quand le soleil était trop baissé, ce n'était pas très agréable de charger ou de décharger à la lumière d'un fanal. On montait sur le pont, on soupait et les gens des autres bateaux arrivaient. Ils avaient leur conteur, eux autres aussi, puis là je leur contais des contes. Puis, le lendemain soir, on était invité sur un autre bateau puis, là, j'écoutais les contes et je me disais : tiens, celui-là, je

et de ses régions voisines - Atlas linguistique de l'Est du Canada, Québec, Éditeur officiel du Québec, «Études et dossiers », 1980, vol. 5, p. 2022-2024 : « Q. 1279 Contracteur forestier »,

28. Baril de clous. 
ne le connais pas, je vais le conter dans les chantiers ». C'est comme ça que le bonhomme, sans le savoir, sans dire le mot, il s'est recyclé. Il sentait le besoin de se recycler parce qu'il m'avait dit : « Je suis embêté de conter toujours les mêmes contes devant les mêmes bûcherons ». Il s'était recyclé et les contes qu'il avait appris sur le bateau, il les racontait dans le chantier. Plusieurs bûcherons, qui suivaient ce bonhomme-là, nous ont dit ça : « Le vieux mosus $^{29}$, il nous contait toujours des contes nouveaux, je ne sais pas où il les prenait, mais il avait toujours des contes nouveaux à nous raconter $\gg$.

\section{"Ils étaient au courant de ce qui était arrivé en Mésopotamie"}

D'un conteur à l'autre, ils apprenaient des contes, ils apprenaient des trucs, des faits qui s'étaient passés. Et là, ils pouvaient composer, mettre ensemble des éléments qu'ils avaient appris dans les contes ou ailleurs. C'est pour ça que je fais la distinction entre composer et inventer un conte. J'en ai vu passablement qui en ont composé. On en a les exemples dans les contes de TiJean joueur de tours : il joue des tours parfois à son roi, parfois à son père, parfois à son seigneur. Ensuite, je ne pense pas que les gens pourraient inventer quelque chose, il faut en avoir eu connaissance. Je ne vois pas qu'un bonhomme qui n'a jamais connu les tours de force d'Hercule ou d'Ulysse puisse inventer des tours absolument semblables. S'il ne sait pas qu'Hercule a lavé l'écurie d'Augias, il n'inventera pas que Ti-Jean est obligé par le roi d'aller laver des écuries. Comment des analphabètes - parce qu'une grande partie de mes conteurs était analphabète comment se faisait-il qu'ils étaient au courant de ce qui était arrivé en Mésopotamie, ce qui était arrivé aux Indes, ce qui était arrivé en Égypte, ne lisant pas ? Comment se fait-il ? Je me suis posé la question très tôt puis je me suis dit : il n'y a pas d'autres moyens que la tradition orale.

29. Mosus (prononcé mosusse), de Moïse en anglais (Moses). Euphémisme pour maudit. Il a ici le sens de ratoureux, rusé. Voir Jean-Pierre Pichette, Le Guide raisonné des jurons, Montréal, Quinze, « Mémoires d'homme », 1980, p. 239. 


\section{"De bouche à oreille [...] les contes très anciens nous sont parvenus "}

En voyant ces contacts-là, ici au Canada ou sous mes yeux, je me suis dit : «Les gens qui ne lisent pas ont entendu. Ils ne peuvent pas lire, mais ils ont des bonnes oreilles et puis ils ont une bonne mémoire ». Alors quand ils entendent un récit, même qui vient de trois mille ans avant Notre-Seigneur - je pense actuellement à Gilgamesh qui a été écrit trois mille ans avant Notre-Seigneur -, [et qu'ils le racontent, je constate] que nos gens connaissent les aventures de Gilgamesh sous un autre nom. Bien Gilgamesh, ç'a été transcrit en assyro-babylonien. L'Assyro-Babylonie 1'a conté à un autre pays, l'Égypte l'a conté... De pays en pays, les gens se racontaient des blagues, des récits, et puis c'est comme ça, je crois, et je ne crois pas être dans l'erreur, que ce sont des contacts par la tradition orale que les gens ont appris des contes et, même si ce sont des contes invraisemblables, des contes merveilleux, des transformations de vieilles chipies, de vieilles sorcières qui transforment ci et ça, même si c'est de la blague, ils ont entendu. Comme ç'a déjà été dit par un conteur, il n'a pas honte de le conter parce qu'il y en a un autre qui l'a conté et puis il n'a pas fait rire de lui. C'est comme ça que, de bouche à oreille, je pense, les contes très anciens nous sont parvenus dans la tradition française. Et les Français sont venus au Canada et nous ont apporté leurs choses. Nous avons transmis plusieurs mythes ou plusieurs récits à nos Indiens et on en a la preuve : Marius Barbeau nous l'a prouvé ${ }^{30}$. Et on sait que certains mythes n’ont pas été inventés par les Indiens, ils les ont appris des gens qui étaient bilingues ou des traducteurs, des gens qui faisaient le commerce des fourrures puis qui leur racontaient des blagues comme ça le soir auprès du feu. C'est comme ça que de bouche à

30. Marius Barbeau a lancé ses enquêtes sur le conte populaire français précisément parce qu'on avait trouvé des contes européens dans la tradition amérindienne et qu'on soupçonnait que les Français en avaient été la courroie de transmission. Voir notre article paru dans ces cahiers : Jean-Pierre Pichette, « Le Lynx et le renard. Un relais déroutant dans la transmission du conte populaire français en Ontario ", dans les Cahiers Charlevoix 1. Études franco-ontariennes, Sudbury, Société Charlevoix et Prise de parole, 1995, p. 169-240, notamment les p. 218-221. 
oreille on peut avoir dans notre répertoire actuellement des contes qui sont multimillénaires. Tout ça, ça revient à la tradition orale. Dans De Sumer au Canada français - Sumer, c'est l'ancien pays de notre ancêtre Abraham, Our en Chaldée ; c'était un Chaldéen, Abraham -, j'ai fait des parallèles entre des aventures de Ti-Jean et des aventures de Hercule, des aventures d'un autre héros de l'Antiquité, j'ai parlé de Gilgamesh, et très souvent c'est quelque chose de frappant ${ }^{31}$.

\section{"Naturellement, on ne l'appelle pas Gilgamesh, c'est toujours Ti-Jean "}

Gilgamesh, je le connaissais par la théologie, l'Écriture sainte. Le professeur nous avait parlé du poème de Gilgamesh. Je ne pensais jamais de rencontrer ça dans les contes, mais non. Je l'ai même en écriture de l'ancienne Égypte, même avant l'Égypte ; l'écriture, c'étaient des dessins ni plus ni moins, des pictogrammes, et puis je l'ai dans des traductions naturellement, en anglais, en latin puis en français. Je l'ai recueilli au moins à deux reprises. Naturellement, on ne l'appelle pas Gilgamesh, c'est toujours Ti-Jean ${ }^{32}$.

\section{"Les contes étaient un système pédagogique qui était fameux dans l'Antiquité" "}

La théorie indianiste, où on prétendait que tous les contes venaient de l'Inde, savez-vous, quand j'ai analysé mon conte - j'ai vu que mon conte qui avait été écrit cinq siècles avant Notre-Seigneur était venu de l'Inde -, j'ai commencé à croire

31. Germain Lemieux, De Sumer au Canada français sur les ailes de la tradition, Sudbury, SHNo, «Documents historiques » 51-52, 1968, 73 p. Voir par exemple en p. $5:$ « Pas un instant nous [n']avons été tenté d'en appeler à la création spontanée, à l'un ou l'autre des 20 siècles qu'a vécus cette légende avant de rejoindre le Canada français. Ce courant de civilisation, dont parle le folkloriste Cosquin, nous est apparu si fort et si impérieux que nous y avons décelé la vraie raison de la longévité de certains récits antiques. »

32. Peut-être la plus ancienne œuvre littéraire de l'humanité, l'épopée de Gilgamesh raconte la quête douloureuse de la fleur qui doit procurer l'immortalité à ce roi d'Ourouk ; une fois cueillie, il la perd par mégarde et doit se résigner à rester un simple mortel. Voir le résumé qu'en donne Germain Lemieux, De Sumer au Canada français sur les ailes de la tradition, op. cit., p. 10-14 : « Gilgamesh, le héros sumérien ». 
que cette théorie-là avait du bon sens parce que l'Inde a produit énormément de choses, et on sait, au moins les historiens le disent, que la civilisation est venue de l'est vers l'ouest. Le pays qu'on connaissait le plus à l'est, qui était très proche de l'ouest peutêtre, c'étaient les Indes. On a pensé que les contes venaient des Indes $^{33}$. Mais, moi, je suis plutôt de l'école de ceux qui pensent que les contes étaient un système pédagogique qui était fameux dans l'Antiquité. On sait par l'histoire que l'Iliade et l'Odyssée faisaient la base de l'éducation des petits Grecs. On les forçait, les pauvres petits Grecs, à apprendre par cœur l'Iliade et l'Odyssée et, naturellement, ils n'apprenaient pas tout seul, on faisait venir des grands savants qui savaient l'Iliade et l'Odyssée et tout ça était accompagné [de musique]. Quand le petit Grec savait à peu près par cœur l'Iliade et l'Odyssée, il savait sa langue ; il savait la poésie parce que tout ça était en poésie ; il savait la technique de la guerre ; il savait la technique de la navigation parce que tout ça était compris là-dedans. Il connaissait tous les dieux parce que, imaginez-vous que, dans l'Iliade et l'Odyssée, il y a des dieux et des déesses qui arrivent constamment. C'était une bible, quoi. Alors le petit Grec qui savait ça était prêt à écrire, il était prêt à chanter parce qu'il apprenait aussi la musique en même temps parce que tout ça était accompagné. On prétend qu'autrefois on enseignait aux enfants des choses très austères, surtout des questions religieuses dans le style du conte et, ça, je serais porté à le penser assez facilement. Moi, j'ai été jeune, on ne croyait pas toujours aux contes, mais il nous en restait quelque chose, comme la façon de raconter. On arrivait à l'école puis on essayait de raconter un bout de conte que le petit vieux nous avait raconté. Les petits Grecs et les anciens se rabattaient comme ça sur des anciennes légendes, des anciens contes, et je suis persuadé qu'ils apprenaient énormément et que c'était un moyen pédagogique efficace.

33. La théorie indianiste a été diffusée en France par les écrits d'Emmanuel Cosquin (1841-1919), notamment ses Contes populaires de Lorraine comparés avec les contes des autres provinces de France et des pays étrangers et précédés d'un Essai sur l'origine et la propagation des contes populaires européens, Paris, F. Viewig, [1886], 2 vol. (LXVII-290 p. ; 376 p.). 


\section{"De la tradition écrite, ça passe à la tradition orale"}

C'est évident qu'à toutes les deux ou trois générations, une pièce qui est écrite va passer à l'oral; elle va être lue par quelqu'un, il faut qu'il sache lire et souvent ce n'était pas lui qui lisait, c'était un autre. J'ai vu ça souvent. J'ai rencontré plusieurs conteurs qui m'ont conté des contes qui se rattachent assez directement aux Mille et une nuits ${ }^{34}$. C'est passé de la tradition écrite, ça passe à la tradition orale et, là, de la tradition orale, d'oreille en oreille, ça peut changer encore. Je pense que c'est un phénomène qui est très vieux, très répandu. Je ne sais pas trop si Adam et Ève savaient lire ou s'ils ont écrit leurs mémoires, mais assez tôt on a eu des systèmes d'écriture pour conserver certains mémoires. Comme le poème de Gilgamesh dont je parlais tantôt, il a été écrit trois mille ans avant Notre-Seigneur et puis il est tombé dans l'oral nécessairement parce que nos gens le content ${ }^{35}$; ils l'ont adapté en Occident et puis c'est un phénomène comme ça constant. Mes professeurs me l'ont dit et je l'ai constaté, simplement par ma petite expérience, qu'il y a des choses écrites qui tombent dans l'oral, l'oral est reproduit et puis ça se suit comme ça de siècle en siècle, de génération en génération. Quand j'ai étudié mon conte pour ma thèse, j'ai constaté surtout que c'était écrit cinq cents ans avant Notre-Seigneur en pali ${ }^{36}$, dans une langue qui avait été oubliée, que ç'avait été traduit en grec, que le grec a été traduit en latin, que le latin a été traduit en anglo-normand, puis les AngloNormands l'ont traduit en français classique et, ensuite, que ç'a pris la voix de la tradition orale. Ce qui veut dire que ce conte, qui a été écrit il y a plusieurs siècles, est parvenu à la connaissance des Français qui l'ont transmis dans la tradition orale. Mais il est mort dans la tradition orale [en France], tandis que, ici au Canada,

34. Par exemple, « Le Prince Kaodad », version recueillie d'Antoine Landry, à Cap-Chat, en 1956, est tirée de 1' « Histoire de Codadad et de ses frères » : voir LVMOC, vol. 22, p. 273-285.

35. Le récit de Gilgamesh, mis par écrit, n'en poursuivait pas moins sa transmission naturelle par voie orale ; à une époque aussi ancienne, il ne peut être question d'influence de l'écrit sur l'oral.

36. Selon le Nouveau Petit Robert, « ancienne langue religieuse de l'Inde méridionale et du Sri Lanka ». 
les vieux Français, nos ancêtres, l'ont raconté et puis il y a une branche au moins de ces contes-là, de Placide-Eustache, qui nous est parvenue par la tradition orale. J'ai constaté par de nombreux manuscrits, de nombreuses publications, que ça passait de l'écrit à l'oral ou de l'oral à l'écrit.

\section{XIV - L'IMPACT ARTISTIQUE ET SCIENTIFIQUE}

\section{"Ces contes-là [...] peuvent inspirer nos artistes"}

J'ai écrit seize volumes de Les vieux m'ont conté qui sont des produits de l'Ontario ; le reste, c'est de l'extérieur. Ce que j'ai écrit, je l'ai écrit, non pas pour montrer que j'étais un savant, mais pour aider notre population canadienne-française. Je me disais que ces contes-là, ces chansons-là, ces légendes peuvent inspirer nos artistes parce que je savais que, dans d'autres pays, c'est ça qui était arrivé... Kodály ${ }^{37}$ par exemple, un Hongrois, se servait surtout de ses enregistrements, et il encourageait ses étudiants à faire de l'enquête et les faire composer de la musique sur les thèmes folkloriques. Je me disais que certainement au Canada nous avons aussi des musiciens, nous avons des artistes, nous avons des gens de la scène qui peuvent utiliser ça. Nos postes de radio - à ce moment-là, il n'y avait pas de télévision -, pourront peut-être sortir quelques programmes et ça sera une espèce de plaidoyer pour conserver le français. Je n'ai jamais dépassé ce but-là, c'était surtout de donner de la matière aux jeunes, aux étudiants du secondaire ou même du primaire, de l'élémentaire, pour les intéresser à la tradition orale. J'ai vu à plusieurs reprises des jeunes conteurs dans la trentaine, trente-cinq, quarante ans, qui contaient à leurs enfants les contes que leur grand-mère leur avait contés quand ils étaient tout petits pour les faire tenir tranquilles.

37. Zoltán Kodály (1882-1967), compositeur et ethnomusicologue hongrois qui a fondé sa méthode d'enseignement de la musique sur la tradition folklorique. Il préconisait que l'enfant apprenne d'abord le chant à partir de la musique populaire comme sa langue musicale maternelle. L'association la Voix de Kodály en France résume ainsi sa pédagogie : "Priorité donnée à la voix et au développement de l'oreille par l'oralité, transmission du patrimoine par la "langue maternelle musicale", modalité plutôt que tonalité comme point de départ à l'apprentissage de la musique ». Source : www.kodaly.fr (consultée le 25 août 2015). 
Je me disais : « Peut-être que si on repique dans la mémoire des jeunes, des chansons, des thèmes de chansons ou des thèmes de contes ou de légendes, quand ils auront trente-cinq, quarante ans, ils sentiront le besoin, quand ce serait seulement pour pacifier leur petite famille, de raconter ces légendes et ces contes-là ». Je ne pensais pas ça à chaque jour, mais c'était latent dans ma tête.

\section{"Je sais que plusieurs s'en sont inspirés"}

Je ne suis pas à même de l'analyser parce que je n'ai pas connaissance de tout ce qui s'est fait à partir de mes publications, mais je sais que plusieurs s'en sont inspirés. Par exemple, un organisme de Sudbury avait composé une couple de pièces ${ }^{38}$; il y avait un conte qu'ils avaient mis sur scène. J'étais allé les entendre et j'avais trouvé qu'ils avaient plus d'imagination que moi. Et puis il y avait un tour de force qui consistait à répéter une chanson casse-cou ${ }^{39}$, comme je disais à ce moment-là, une chanson à accumulation. Le concours, c'étaient deux, trois artistes sur la scène qui s'entraînaient à des chansons casse-cou et qui réussissaient pas mal. J'avais trouvé qu'ils étaient ingénieux d'imagination. J'avais été emballé par leur mise en scène, que je n'aurais pas osé faire, moi, que je croyais irréalisable, mais, eux autres, ils étaient capables de le faire. Je sais qu'on s'est servi de temps en temps de mes chansons dans les classes, surtout pour des chansons à répondre, des chansons canadiennesfrançaises, des chansons de circonstance. La chanson Le Petit Mari a été chantée à certains endroits pour donner un exemple de rythmique. Dans l'ensemble, je ne pourrais pas dire que ç'a eu un impact extraordinaire, mais plusieurs m'en ont parlé après coup, qui fouillaient, qui lisaient ces contes-là pour chercher de l'inspiration, soit pour quelque chose de réalisable en classe ou dans la communauté.

38. Il s'agirait de pièces montées par le Théâtre du Nouvel-Ontario à partir des contes facétieux de Ti-Jean.

39. Selon Conrad Laforte, il s'agit de la chanson énumérative à reprise récapitulative, dont la formule strophique s'allonge à chaque couplet. Voir Poétiques de la chanson traditionnelle française, Deuxième édition, Québec, Presses de l’Université Laval, «Archives de folklore » 26, 1993, p. 84. 


\section{"Camille Perron... il était un bon conteur"}

Des chercheurs ont réalisé des œuvres, importantes parfois, en se basant sur mes contes, sur les légendes. Je pense à une Franco-Ontarienne, Claire Guillemette-Lamirande ${ }^{40}$, qui a fait de belles peintures et qui a inspiré d'autres artistes de l'Acadie. Ils ont fait plus que des toiles : des murales; et ils ont épaté tout le monde qui ont [a] assisté à ces expositions-là. Ensuite, il y a Luc Robert qui a fait des bandes dessinées qui ont une bonne valeur $^{41}$. Ça lui a valu d'être obligé de lire des contes et de me consulter pour voir s'il n'allait pas trop loin ou parfois si le roi avait l'air trop guenillou, si on devait lui mettre une couronne en tête ; alors on discutait de ça. Je trouve qu'il a très bien réussi son but dans les bandes dessinées. Il y a Camille Perron qu'il ne faut pas oublier parce qu'il a mis en valeur une grande partie de notre répertoire de contes, de légendes, et il était un bon conteur ${ }^{42}$. C'était un conteur intelligent, et puis on voyait qu'il croyait à ce qu'il disait; non seulement il y croyait, mais il voulait rendre à ces pièces-là toute leur lumière artistique, je dirais. Il est venu souvent à notre centre de folklore et il me demandait [qui étaient] pour moi les meilleurs conteurs, pour voir leur gestuelle parce qu'il croyait lui au port de voix, au sens de la voix et du geste. Il passait des heures et des heures, à ma connaissance, devant des films que j'avais enregistrés de monsieur Saint-Louis de la Gaspésie. Je me rappelle qu'il faisait jouer à plusieurs reprises tel passage où il était en extase devant la mimique de ce vieux-là et sa gestuelle. Je l'ai vu et entendu à plusieurs reprises, et j'ai vu qu'il donnait une valeur, une dimension extraordinairement

40. Claire Guillemette-Lamirande (Timmins, 1938-Sherbrooke, 2010) s'est inspirée des contes populaires franco-ontariens dans sa peinture et sa tapisserie. Yolande Grisé, Contes et couleurs de l'Ontario français (Ottawa, Centre francoontarien de ressources pédagogiques, 1979), présente neuf aquarelles illustrant les contes du premier tome de la série Les vieux m'ont conté de Germain Lemieux.

41. Luc Robert a participé à la diffusion des travaux du Centre franco-ontarien de folklore, notamment par la bande dessinée : en collaboration avec le père Germain Lemieux, il a illustré le conte Ti-Jean fin voleur, Prise de Parole et Centre francoontarien de folklore, 1992, $24 \mathrm{p}$.

42. Camille Perron (1929-1995). Voir Georges Bélanger, « Camille Perron, néo-conteur franco-ontarien », Francophonies d'Amérique, n 5, 1995, p. 59-65. 
artistique de nos contes, de nos légendes. Maurice Gaudreault, je ne dirais pas qu'il s'est inspiré uniquement de mes contes et de mes légendes, mais lui aussi a été piqué par le microbe de la tradition orale ${ }^{43}$. Il représente des scènes extraordinairement paysannes et canadiennes, soit dans les chantiers ou le conteur devant un foyer, par exemple le curé qui bénit les saintes huiles, qui bénit les grains, certaines scènes comme ça, chrétiennes qu'il a illustrées très bien. Maurice Gaudreault, sur lequel on compte bientôt pour nous faire une exposition parce qu'on le considère comme un représentant extraordinaire de la tradition orale ${ }^{44}$.

\section{"La tradition orale n'était pas morte"}

J'ai écrit dans Placide-Eustache que je comptais sur la jeune génération pour sortir de la caverne le trésor que les ancêtres y avaient caché ${ }^{45}$. Je pensais à l'avenir et aux jeunes. J'ai enseigné assez longtemps le folklore et même l'histoire, et je m'apercevais que mes étudiants passionnés par cette matière-là, un jour ou l'autre, [allaient] percer, faire de l'enquête et se sentir capables de me remplacer. On en avait formé quelques-uns ; mais, malheureusement, quand ils étaient prêts, nous n'avions pas de finance pour les faire vivre. C'était une autre déception que j'ai eue, à plusieurs reprises. J'ai pensé couramment à cette jeune équipe, cette jeune génération capable de me remplacer. Je n'ai pas été déçu entièrement parce qu'il y en a plusieurs actuellement à

43. Maurice Gaudreault (Moonbeam, 1932-Fauquier, 2000), sculpteur sur argile dont la première exposition, intitulée "J'ai souvenir encore » (1993), se voulait un hommage au travail des pionniers nord-ontariens. Sources : crccf.uottawa. ca/passeport/II/Cla/IICla03-4.html (consultée le 25 août 2015) ; Paul-François Sylvestre, "Les hiers. Naissance du sculpteur Maurice Gaudreault », L'Express de Toronto, semaine du 25 septembre au 1 octobre 2007 ; www.lexpress.to/archives/1786 (consultée le 25 août 2015).

44. Allusion à l'exposition «Celui qu'on appelle Jésus », inspirée des récits évangéliques, qui était annoncée et qui fut présentée en 1996.

45. Germain Lemieux, Placide Eustache. Sources et parallèles du contetype 938, Québec, Presses de l'Université Laval, "Archives de folklore » 10, 1970, p. 7 : «Les anciens nous ont indiqué l'entrée de la caverne où le trésor est caché; se trouvera-t-il une équipe de jeunes intellectuels capables de partir à la conquête et à l'exploitation de cette richesse nationale?» 
l'Université de Sudbury, au département de folklore, qui se lancent dans l'enquête et qui continuent. Il reste certainement encore des filons à exploiter. J'entendais dernièrement un enregistrement, fait peut-être il y a quelques mois, de chansons que j'avais recueillies, moi, il y a trente ans, quarante ans ; je voyais que le chanteur avait à peu près les mêmes versions et qu'il avait le même accent paysan et que la tradition orale n'était pas morte.

\section{"Refaire des contes neufs avec du vieux matériel "}

Que l'avenir de ces contes, de ces légendes, de ces chansons, l'avenir du folklore soit assuré, moi aussi j'en suis [persuadé]. On le voit par le nombre de publications qui se font actuellement, le nombre de séances de contes qu'on organise à Montréal ou même ici, à Sudbury. Dernièrement, un monsieur Campiche ${ }^{46}$, de Suisse je crois, est venu nous épater. On voit que leur tradition orale rejoint un peu la nôtre ; ces artistes-là viennent nous apporter ce que leur tradition orale leur a donné. Et cet artiste a été un peu surpris de voir que nous avions tant de contes ici. Il a promis d'acheter la collection et de l'exploiter, c'est-à-dire de refaire des contes neufs avec du vieux matériel qu'on a recueilli ici. Je suis

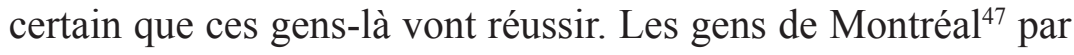
exemple - j'y suis allé l'an dernier - ont renouvelé cette année leur invitation à [collaborer] et envoient à Sudbury des conteurs qui ont de l'étoffe excessivement précieuse ; qui ont le sens du public, le sens du conte, le sens de la tradition orale quoi. Je ne dirais pas que j'approuve totalement, que je suis épaté toujours par leurs trouvailles ou par le style... parce que j'étais habitué au style ancien, le style oral, et parfois je trouve que c'est un peu neuf pour moi. Ils innovent, je ne dis pas que c'est mauvais, que ça va tuer la tradition orale, mais non ; ils racontent au moins. Les gens qui les entendent sont tellement touchés par le sens artistique

46. Philippe Campiche, conteur suisse, venu à Sudbury en 1995.

47. Fondé en 1993, le Festival interculturel du conte du Québec, qui se déroule à Montréal, a nommé le père Lemieux président d'honneur en 1994 et l'a présenté le jour de l'inauguration le 4 novembre 1994. 
de ces artistes-là qu'ils vont être portés eux aussi à propager les contes, les légendes qu'ils savent, qu'ils ont dans leur mémoire ou qu'ils acquièrent en lisant nos publications.

\section{"Les enquêtes qui sont menées actuellement promettent énormément"}

C'est un fait que l'enquête se généralise actuellement, que nos gens sont plus inspirés, respectent plus la tradition orale, ce qu'on appelle le patrimoine, que nos gens sont plus au courant du patrimoine national qu'autrefois. Monsieur Lacourcière, comme monsieur Marius Barbeau qui nous a stimulés à enquêter dans le domaine de la technique artisanale, dans le domaine du conte, de la chanson, monseigneur Savard et nos professeurs nous le disaient : «Tâchez de stimuler vos élèves - nous étions à peu près tous des professeurs - à enquêter, à s'intéresser à leur milieu, au patrimoine, à la tradition orale, et vous allez avoir peut-être des surprises ». Le fait est que, à force de répéter en classe ce que nos professeurs nous ont dit, les enquêtes qui sont menées actuellement promettent énormément pour l'avenir. Je trouve qu'ils sont plus chanceux que nous autres qui n'avions pratiquement pas d'instruments, qui n'avions pas de formation. Moi, j'ai commencé à improviser mes enquêtes. J'imagine que Marius Barbeau avait une formation plus profonde que la mienne et que celle de monsieur Lacourcière. Les gens actuellement qui se lancent dans l'enquête ont plus de formation que nous avions ; ils ont plus de matériel aussi, l'électronique est à leur portée et ils sont assez intelligents pour s'en servir. Alors je compte sur les moyens actuels qui viennent en aide aux enquêteurs qui vont appuyer nos études ou les efforts qu'on a faits pour maintenir la tradition orale.

\section{"J'ai persévéré" "}

Mon plus grand motif de fierté, après cinquante ans de travaux, difficiles souvent, c'est d'avoir persévéré. J'ai rencontré beaucoup de difficultés et puis je me disais : " Je ne lâche pas ». Je pense 
que mon plus grand motif de fierté c'est d'avoir persévéré et d'avoir montré à la jeune génération, à mes élèves, que c'était possible de faire ces enquêtes, souvent dans une atmosphère nébuleuse, nuageuse, et qu'on peut passer à travers; il s'agit de tenir, de ne pas lâcher. Je pense que mon plus grand motif de fierté, c'est d'abord d'avoir compris les paysans qui m'ont donné leurs documents, les avoir aimés, de ne pas les avoir trahis et d'avoir persévéré jusqu' au moment où on peut mettre à la portée du public les documents qu'ils avaient conservés depuis des générations dans leur mémoire.

\section{"C'était une grande déception"}

Les déceptions, ç'a commencé assez tôt. J'ai rappelé auparavant que j'avais été dénoncé auprès de mes supérieurs comme faisant un travail qui ne valait rien et que, surtout au point de vue moral, c'était dangereux d'aller deux fois dans la même maison et de ne pas avoir de surveillant. Je m'en suis tiré assez facilement ${ }^{48}$. Une autre grande crainte : au moment où l'Université de Sudbury s'organisait, quelqu'un voulait s'emparer de la collection, qui appartenait à la Société historique, dans un but financier, pour vendre ça, croyant qu'ils allaient avoir un demi-million pour à peu près 500 documents qu'on avait à ce moment-là. Je me rappelle d'avoir passé une nuit jusqu'à deux heures et demie du matin chez un avocat, où il y avait un juge aussi, pour examiner la jurisprudence, parce qu'on nous attaquait comme ceci : la Société historique n'est pas incorporée - c'était vrai - donc tout ce que la Société historique a fait, ça appartient à ceux qui l'ont constituée, donc aux jésuites et au collège du Sacré-Cœur. On a découvert qu'une association qui était considérée pendant un certain nombre d'années, six ou sept ans, comme indépendante, ça valait une incorporation. La Société historique à ce momentlà siégeait au collège de temps en temps, au moins une fois par mois ; les membres payaient leur café, ils payaient leur salle

48. Voir le premier volet de cet entretien, « Germain Lemieux par lui-même (1914-1958) », Cahiers Charlevoix 9, op. cit., p. 189 : « Mon premier mémoire sur la technique de l'enquête ». 
et puis ils avaient été sollicités à deux reprises au moins pour collaborer à une levée de fonds ${ }^{49}$. C'étaient des documents qui équivalaient à une incorporation ${ }^{50}$. À une autre reprise, plus tard, d'autres voulaient s'en emparer pour mettre ça dans des caves pour les protéger; les protéger, ça voulait dire que personne n'y ait accès. Il y avait encore des gens, dans les années 19801990, qui n'avaient pas du tout découvert la richesse de notre documentation $^{51}$. Ça faisait quarante ans que je travaillais, $j$ 'avais eu quelques récompenses, une médaille de temps en temps. Je croyais que ç'aurait pu influencer notre entourage à réfléchir, voir si c'était simplement la réaction de la galerie ou bien si c'était vraiment fondé. Ça, c'était une grande déception de voir que des gens n'avaient pas compris la valeur de la tradition orale et qu'ils ne faisaient rien du tout pour aider les organismes à s'inspirer de cette documentation-là pour prolonger la recherche dans le domaine historique ou dans le domaine folklorique. Mais on s'en est tiré encore assez élégamment.

\section{"Ça m'a énormément touché "}

Des honneurs qu'on m'a accordés, je pense que celui qui m'a le plus touché, qui m'a le plus surpris, c'est celui de 1991 : le symposium qui a réuni des gens, même d'Europe, des gens du Québec, des gens de l'Ontario, de différents organismes, et qui sont venus me rendre hommage. Surtout, je savais que ce n'était pas nécessairement moi, avec mon beau toupet qui était tombé, qu'on honorait, qu'on reconnaissait, mais c'était mon œuvre ${ }^{52}$.

49. Calque de fund raising, collecte de fonds, souscription, campagne de financement.

50. Les inquiétudes que manifeste cet épisode, à situer probablement en 1958 aux premiers temps de l'Université de Sudbury, mèneront à l'incorporation du Centre franco-ontarien de folklore en 1972 afin de protéger l'intégrité de sa collection documentaire.

51. Cet épisode correspond au rectorat (1976-1982) du père Lucien Michaud (1925-2006), au moment où le père Lemieux quitta l'Université de Sudbury pour s'installer en ville au Centre des jeunes en 1981. La mésentente dura pendant le rectorat (1982-1992) de son successeur, le père Laurent Larouche (1924-2010).

52. L'Euvre de Germain Lemieux, s.j. Bilan de l'ethnologie en Ontario français. Actes du colloque tenu à l'Université de Sudbury les 31 octobre, 
Ç’a touché aussi même des gens de la Gaspésie, de ma famille, et même un maire d'une municipalité ${ }^{53}$. Ils savaient ce que j'avais fait, mais ils voulaient voir ce que d'autres chercheurs pouvaient dire de moi, ce qu'ils avaient trouvé qu'eux autres n'avaient pas trouvé. Et ça, ça m’a énormément touché.

\section{"Le nain qui est porté sur le dos d'un géant"}

Ces honneurs que j'ai reçus, médailles, parchemins ou autres manifestations, je croyais que ça visait surtout les gens qui m'avaient aidé, tous ces informateurs, pour une grande partie analphabètes, qui avaient consacré des heures et des heures, je pourrais dire des années, à m'endurer. Ce sont ces gens-là que je voulais remercier et que je croyais que les gens du symposium remerciaient. Alors je pensais à tous ces gens-là, que c'est eux autres qui auraient dû recevoir les honneurs, c'est eux autres qu'on aurait dû réunir, mais malheureusement la plupart étaient déjà décédés. Oui, je me suis servi de temps en temps de cette figure de style - le nain qui est porté sur le dos d'un géant - pour montrer qu'au fond je n'étais pas grand-chose comparé à d'autres qui avaient fait beaucoup plus que moi, peut-être avec des moyens moindres que les miens.

\section{"Les jésuites [...] m'ont appuyé tout le temps"}

D'abord en 1991, le provincial des jésuites du Canada français avait envoyé son représentant ${ }^{54}$. Il m'avait envoyé une belle lettre lui-même. Ensuite, il n'y avait pas seulement le provincial qui était à 450 milles, et son représentant qui vivait aussi à Montréal, qui venaient reconnaître la valeur de mon œuvre. Les louanges du père Girouard ${ }^{55}$ venaient montrer que même les jésuites de la

$1^{\text {er }}$ et 2 novembre 1991, sous la direction de Jean-Pierre Pichette, Sudbury, Prise de parole et Centre franco-ontarien de folklore, «Ancrages » $\mathrm{n}^{\circ} 2,1993,529 \mathrm{p}$.

53. Monsieur Augustin Saint-Laurent, maire de Cap-Chat.

54. Germain Lemieux, « Mon projet folklorique cinquante ans plus tard», dans L'Euvre de Germain Lemieux, s.j., op. cit., p. 21 : le père Jean-Marie Archambault, provincial, avait délégué « son conseiller spécial, le père Rémi Potvin ».

55. André Girouard, s.j. (Thetford-les-Mines, Québec, 1925-Saint-Jérôme, 
région [appréciaient mon travail et elles m'ont touché]. Le père Girouard m'avait vu marcher assez rapidement dans les corridors, partir avec ma vieille machine ${ }^{56}$ pour Hearst ou pour Timmins ; peut-être qu'il se disait : «Est-ce qu'il va se rendre ? Est-ce qu'il va revenir ? Est-ce qu'il va recueillir quelque chose ?» Il y en a plusieurs autres qui disaient ça, souvent parce que j'avais toujours une vieille voiture qui ne servait plus ou qui était démodée. Je m'arrangeais assez facilement de ça, heureux de voir que la communauté d'abord m'accordait une voiture et payait mes dépenses, mon essence, etc. Il faut que je le dise encore une fois que, si ça n'avait pas été de la communauté des jésuites, je n'aurais pas été loin ${ }^{57}$. Si on m'avait dit: «Écoute un peu, on n'a plus les moyens de payer ton essence, on n'a plus les moyens de réparer ta vieille voiture, va à pied »; ça, ç'aurait été une grosse déception et on ne l'a pas fait. Je peux rendre ce témoignage-là que la communauté des jésuites de Sudbury et même de Montréal m'ont appuyé tout le temps. C'est eux autres qui sont les grands responsables de mes travaux parce que, moi,j'aurais fait n'importe quoi. Et le fait qu'on m'ait permis de faire du folklore, de me lancer dans ces travaux-là, ç'a été une grande consolation. Les jésuites de Sudbury y allaient de sommes assez considérables pour m'appuyer ; ça encore, je [leur] dois des remerciements et je ne saurais les remercier trop et trop souvent.

Québec, 2009), professeur de littérature française à l'Université de Sudbury (19581960) puis à l'Université Laurentienne (1960-1986), collaborateur à l'hebdomadaire Le Voyageur à titre de journaliste (1986-1995) et à d'autres périodiques (Chez nous, Directions). Voir son témoignage : «Un ethnographe chez les jésuites de Sudbury », L'Euvre de Germain Lemieux, s.j. op. cit., p. 137-146 ; notamment sa conclusion, p. 146 : «Durant plus de cinquante ans, le père Lemieux a travaillé avec une régularité, une constance finalement si discrète, que nous oubliions de voir l'énormité du travail qui s'accomplissait sous nos yeux distraits. Aujourd'hui, nous voyons et nous admirons. »

56. Machine a ici le sens d'automobile.

57. En dépit de l'incompréhension de certains confrères jésuites, évoquée plus haut, Germain Lemieux a toujours cru que, sans son ordre religieux, il n'aurait pu accomplir son œuvre. Voir le deuxième volet de cet entretien, "Germain Lemieux par lui-même (1952-1995) ", Cahiers Charlevoix 10, op. cit., p. 142-143 : "Un laïc n'aurait pas été capable de faire ça». 
XV - UN FOLKLORE FRANCO-ONTARIEN

\section{"Ils sont différents des Québécois"}

Je suis en Ontario depuis plus de cinquante ans et j'ai remarqué une différence entre la mentalité québécoise par exemple, ou acadienne, ou gaspésienne, et c'est frappant. Un professeur à l'Université Laval avait laissé entendre devant la classe que, si les Québécois ne s'étaient pas remués plus que les Franco-Ontariens, ils auraient perdu leur langue et leur culture. Il avait dit que les Anglais, c'était la politique des cold facts [faits bruts] et ils allaient plus lentement. Après la classe, je lui ai dit : «J'ai apprécié le fait que vous ayez analysé le flegme anglais, mais, si les Canadiens français de l'Ontario avaient fait comme les Québécois, publier leurs annonces seulement sur le perron de l'église et ensuite retourner chez eux, ils n'auraient pas aboli le Règlement XVII. - Vous êtes au courant du Règlement XVII, depuis 1913, qui a été abrogé en $1927^{58}$. - S'ils avaient bataillé, s'ils avaient criaillé dans les rues, ils n'auraient pas obtenu l'abolition. Ils ont saisi la politique anglaise, qui est de ne pas parler et de travailler en dessous ; c'est comme ça, je pense, qu'ils ont survécu et que, actuellement, ils ont d'assez bonnes positions au point de vue linguistique, au point de vue culturel ». Il y a certainement une différence dans le tempérament : le fait que les Franco-Ontariens aient côtoyé les anglophones et même, je dirais, les allophones et surtout les Ojiboués ${ }^{59}$, ça leur a donné quelque chose ça. Dans leur prononciation, dans leur mentalité et dans leur comportement, ils sont différents des Québécois.

\section{"Le folklore [...], je crois que ça les incitait à parler français "}

Entre le folklore et la survivance franco-ontarienne, je pense qu'il y a un lien assez étroit. Je me suis aperçu en enquêtant que les gens se sentaient fiers d'avoir conservé un vieux répertoire francophone

58. Adopté par le gouvernement de l'Ontario en 1912, le Règlement XVII faisait de l'anglais la langue d'instruction dans toutes les écoles de la province. Voir le premier volet de cet entretien, « Germain Lemieux par lui-même (1914-1958) », Cahiers Charlevoix 9, op. cit., p. 168, note 103.

59. Francisation du nom Ojibwa ou Anishinaabeg. Ibid., p. 172, note 107. 
rapporté du Québec, lequel répertoire francophone venait de la France. Ils sentaient une certaine fierté d'avoir conservé leurs légendes, beaucoup de contes. Monsieur Lacourcière m'a dit, au début des enquêtes, que j'avais recueilli des contes et des chansons qu'il n'avait pas recueillis dans le Québec. Ça ne veut pas dire qu'ils n'existaient pas dans le Québec, mais il ne les avait pas recueillis encore. Quelqu'un m'a dit qu'il avait entendu une vieille dame qui ne savait plus le français, mais qui lui avait raconté une légende en français. Elle ne pouvait pas dialoguer en français, mais elle savait encore assez son français pour conter une légende en français. Ça veut dire ça qu'il reste encore un peu de français dans l'Ontario grâce à ça : les gens se sont rabattus là-dessus et je suis certain, moi, qu'il y a des Franco-Ontariens qui ont appris à discuter et qui ont appris à se défendre en français parce qu'ils étaient habitués de raconter des contes et des légendes, chanter des chansons en français et qu'ils étaient appréciés. Je pense que, au moins dans certains coins, ç'a été un rempart, le folklore, la tradition orale, dans le domaine de la technique artisanale, dans le domaine de la chanson, dans le domaine du conte et de la légende ; ç'a été une sauvegarde. Quand nos jeunes Franco-Ontariens entendaient leur père ou leur grand-père raconter une légende en français, je crois que ça les incitait à parler français et ça leur donnait une fierté qui les mettait en garde contre l'assimilation. Je ne dis pas que ç'a fonctionné partout, mais je suis certain que, dans certains coins, surtout ici dans notre coin de Sudbury, où on a peut-être la plus grande proportion de Canadiens français, que ç'a joué, ça.

\section{"Sudbury, c'était le rendez-vous d'une multitude de Canadiens français "}

En enquêtant à partir de 1948, je me suis aperçu que, dans la région de Sudbury, il y avait énormément de francophones. Il faut souligner ensuite que Sudbury même, c'était le rendez-vous d'une multitude de Canadiens français qui venaient de plusieurs paroisses du Québec. Je me rappelle très bien que j'enquêtais 
un soir d'un côté de la rue et je rencontrais un Madelinot, et, le lendemain soir, je traversais la rue et puis un Gaspésien qui était là me disait : «Il y a un Acadien pas loin ». C'était un rendez-vous de francophones du Québec ou des provinces maritimes, et ces genslà tenaient à raconter leurs légendes en français et à chanter leurs chansons en français, qui étaient un vieux répertoire francophone qui leur venait des ancêtres. J'ai rencontré un monsieur de quatrevingt-quatre ans, en 1954-1955, à Neuville [Québec], qui avait gagné sa vie pendant sept ou huit ans à Copper-Cliff, et il m'a donné des souvenirs. À ce moment-là, il n'y avait pas d'usine, il n'y avait pas de fournaise, il n'y avait pas de haut-fourneau, et on coulait le minerai à ciel ouvert. Les gens empilaient des billots pendant des mois et des mois, et ensuite ça leur prenait des mois à basculer du minerai de fer ou d'aluminium sur ce bois-là ; ils allumaient le feu et, là, ça faisait un feu extraordinaire, tellement chaud que ça fondait le minerai. Il me disait qu'ils respiraient le souffre à pleins poumons et c'est ça, paraît-il, qui aurait massacré la végétation de Sudbury et de vingt milles alentour. En 1941, les cultivateurs actionnaient la compagnie de l'Inco parce qu'ils faisaient mourir leur récolte. Au début, ce monsieur-là me disait qu'à Sudbury parfois l'atmosphère était irrespirable. Les gens sont venus de l'Acadie, de la Gaspésie, d'un peu partout pour gagner leur vie, soit à Copper-Cliff, soit à Sudbury, parce que beaucoup ont travaillé sur les chemins de fer et puis dans des hôtels. Un de mes vieux oncles m'avait dit qu'en 1883-1884 il était venu à Sudbury ; il était de passage et il était allé dans un petit hôtel et il avait payé vingt-cinq sous pour coucher et déjeuner. Il se rappelait le nom de la tenancière, c'était une bonne Gaspésienne. C'était le rendez-vous. Ensuite, quand les gens s'en allaient dans l'Ouest, ils faisaient un pied-à-terre assez long ici à Sudbury pour reprendre le train ou pour refaire leurs finances pour être capables de se rendre jusque dans l'Ouest.

\section{"Une situation providentielle pour l'étude du folklore"}

Oui, je l'ai déjà dit et je le croyais, que c'était une situation 
providentielle pour l'étude du folklore que d'être à Sudbury; et j'y crois encore, justement à cause de ce rendez-vous des gens qui sont venus gagner leur pain, surtout à Copper-Cliff. Si j'étais resté à Montréal ou dans ma Gaspésie natale, ou même à Québec, je ne crois pas que ma carrière aurait été aussi fulgurante que ça - quoiqu'il n'y a pas beaucoup d'étincelles qui soient sorties de là - ; mais je n'aurais probablement pas suivi la même route parce que, ici, j'ai rencontré un milieu qui était sympathique et je me suis aperçu, dès le début, qu'on tenait au français. Je suis arrivé en 1941 pendant la guerre. Et même si quelques-uns nous criaient « speak white ${ }^{60}$ », ça ne nous énervait pas et on continuait à parler français parce qu'on savait qu'il y en avait d'autres francophones qui nous attendaient et, surtout, on avait le collège du Sacré-Cœur qui a été une espèce de fortification, une place fortifiée du français. Tous les francophones de Sudbury et des environs, tous les organismes, venaient à tour de rôle au collège du Sacré-Cœur, soit pour bien profiter des conseils de gens qui étaient ancrés dans la culture francophone et, ça, ça nous donnait un peu de courage. Ensuite, je me suis aperçu, moi, que ces va-etvient de francophones qui venaient au collège étaient bons pour l'enquête. Alors c'est comme ça qu'en 1948 je me suis lancé, sous prétexte de voir si vraiment il y avait encore de l'esprit français dans la région. On a répondu affirmativement et, après quelques enquêtes, même la Société historique qui me patronnait a conclu que vraiment les gens étaient encore décidés à parler français dans la région ; et c'est pour ça que j'ai commencé ma carrière pratiquement ici, à Sudbury, et que je l'ai continuée pendant des années, au-delà de cinquante ans.

\section{"Il y a un folklore franco-ontarien"}

Lors d'une rencontre, à Ottawa ou à Montréal, une petite dame s'était levée, presque en colère, et m'avait dit : «De quelle autorité pouvez-vous signifier qu'il y a un folklore franco-ontarien? » Je

60. Insulte raciste qui pourrait s'entendre ainsi : parle anglais en public comme les Blancs. 
lui ai répondu, un peu comme les anciens philosophes grecs, par des questions : «Est-ce que vous admettez que les Gaspésiens par exemple ont leur folklore ? » Elle a dit oui. « Est-ce que les Acadiens n'auraient pas aussi leur folklore ? - Mais si, ils ont leur folklore. - Est-ce que les Beaucerons auraient leur folklore? - Mais oui. - Comment définissez-vous le folklore acadien et gaspésien, par quoi ? « Elle n'a pas pu me répondre. J'ai dit : « Je vais vous dire maintenant pourquoi, moi, j’ai décidé de baptiser notre folklore de là-bas franco-ontarien. C'est parce que nous avons plusieurs légendes ici dans notre milieu. Nous avons un répertoire qui est un peu différent. En comparant des contes par exemple que j'avais recueillis dans la Gaspésie, puis ceux d'un vieux monsieur de quatre-vingt-deux ans qui avait appris ses contes en 1870-1872 dans un chantier des États-Unis, je me suis aperçu que tout ce qui regardait la marine avait été supprimé dans les contes franco-ontariens et il amplifiait plutôt les descriptions des chantiers, de la forêt, des voyages. Ça, c'est quelque chose qui, à mon avis, est spécifique des Franco-Ontariens. Ensuite, ils ont la langue. Les Acadiens ont leur langue, les Gaspésiens ont leur langue, leur prononciation, leur vocabulaire ; les Franco-Ontariens eux autres aussi. J'avais remarqué, d'après mes enquêtes que j'avais faites en Acadie et ici, qu'il y avait moins d'anglicismes peut-être dans le folklore franco-ontarien que dans le folklore acadien, une prononciation un peu différente : leur $\langle r$ » est un peu différent, leur « $t$ »va être un peu différent, parfois il y a des sifflements de « $s$ » qu'on ne rencontrera pas ailleurs. J'ai dit: «C'est pour ça, je pense, que le folklore franco-ontarien a sa place ; on peut l'appeler franco-ontarien pour les raisons que je vous donne : on a nos légendes, on a notre répertoire de contes qui est un peu différent de ceux des autres régions, on a des chansons qui sont chantées souvent [avec] des retranchements, des ajouts dans les couplets qui sont réellement franco-ontariens. C'est pour ça que je pense que j'ai raison d'appeler le folklore en dehors du Québec, ici de l'Ontario, de l'appeler franco-ontarien ». La dame a accepté ma définition. Monsieur Lacourcière était de la 
partie et $\mathrm{j}$ 'avais offert à monsieur Lacourcière de répondre, mais il m'a dit non. Après il m'a dit : « Je pense que vous avez bien répondu ». À ce moment-là, on parlait de la francophonie, des Franco-Ontariens. Quand je suis arrivé en 1941, au moins les gens qui ont fondé la Société historique en 1942 parlaient de la culture franco-ontarienne, de la langue franco-ontarienne assez couramment. Je me suis servi des éléments qui existaient déjà.

\section{XVI - Du collège du Sacré-Ceur à l'Université... FRANCO-ONTARIENNE}

\section{"Le collège du Sacré-Cour a été un rempart contre l'anglicisation"}

Le collège du Sacré-Cœur a été un rempart contre l'anglicisation en Ontario. Il a fermé ses portes en 1967 et je sais qu'il y a eu beaucoup de récriminations, beaucoup de protestations. Mais ils ont dit : « Le collège du Sacré-Cœur, ça va être l'Université de Sudbury, on va avoir le même service qu'on avait au collège du Sacré-Cœur ». Je laisse à d'autres de juger si c'est exact; mais je sais que, depuis ce temps-là, on a regretté. Je me rappelle une de mes premières années où j'ai enseigné à l'Université Laurentienne. On avait des gens qui venaient du collège du SacréCœur et d'autres qui venaient du high school [école secondaire de langue anglaise], et puis il y avait une grosse différence dans l'éducation, dans la formation. Je pense que le collège du SacréCœur, même s'il était très pauvre, je ne crois pas qu'il ait envoyé des gens qui ne sachent pas leur français, non. Le préfet d'étude était toujours là pour nous dire qu'il fallait enseigner le français en français et, quand on enseignait la traduction latine, c'était du latin au français, quand on traduisait du grec, c'était en français ; et de s'appliquer à donner une bonne traduction et de s'aider par exemple des racines grecques, des racines latines, pour montrer aux étudiants d'où viennent nos mots français qui sont passés par la France, naturellement par les Gaulois. Les racines grecques, les racines latines, on insistait énormément là-dessus pour enrichir le français. Est-ce qu'on fait ça encore ? Comme je n'enseigne 
plus dans les institutions canadiennes-françaises qui sont sorties du collège du Sacré-Cœur, je ne peux pas me prononcer.

\section{"Que nos contes... servent à la recherche"}

Je n'ai pas encore quatre-vingt-dix ans, mais je peux faire des souhaits aux jeunes, c'est-à-dire les jeunes qui ont soixante-dix ans, soixante ans ou cinquante ans. Mon plus grand souhait, ce serait que tout ce que j'ai recueilli - je dis « je», mais je devrais dire «nous » parce que je ne suis pas seul; et je le maintiens pour ceux qui voudraient dire que je suis le seul responsable : non, je ne suis pas le seul responsable de la cueillette que j'ai faite ou des enquêtes que j'ai faites ou même des articles que j'ai écrits, c'est nous - ; alors, la documentation que nous avons recueillie, je voudrais qu'elle aboutisse quelque part, non pas dans une cave dans des caisses, mais qu'elle aboutisse dans une institution qui puisse s'en servir pour étudier davantage la langue française, pour intéresser les étudiants de cette institution, que ce soit une université ou que ce soit un collège, peu importe, que ça serve à quelque chose ; que nos contes, que nos chansons, que nos légendes, que nos techniques artisanales servent à la recherche. Et ça, je crois que je n'aurais pas perdu mon temps, que nous n'aurions pas perdu notre temps à empiler des documents, soit des documents sonores ou des documents écrits de tout mon matériel, s'il y avait une relève, si dans une institution qui se servait sérieusement de cette documentation-là pour faire la recherche chez nos étudiants, qu'ils retrouvent la technique artisanale des ancêtres, le génie des ancêtres, parce que nos ancêtres avaient certainement le génie, simplement à regarder les outils qu'ils nous ont laissés.

"Une université française en Ontario... ce serait une bénédiction"

Une université française en Ontario. Je pense que ça serait le rêve de plusieurs. Je pense que ce n'est pas mort, l'idée n'est pas morte. Je sais qu'encore dernièrement, il n'y a pas plus que deux ou trois 
mois, les jeunes ont discuté encore ce problème-là, et puis je crois que ça donnerait une occasion à nos Franco-Ontariens d'étudier sur place le français, ne pas avoir besoin d'aller à Montréal ou d'aller à Québec pour étudier le français à fond et de prendre des degrés en français. Je crois que ce serait une bénédiction; pas parce que je le souhaite, mais parce que c'est un fait. Quand on parle qu'on ne peut pas ouvrir d'université ou d'institution francophone, d'institution universitaire à cause de la finance, ça je crois que personne n'y croit. Il y aurait moyen avec les cent millions, cent dix millions, que Toronto donne aux universités bilingues, il y aurait moyen d'en prendre une petite moitié puis de créer une bonne université francophone qui soit solide, qui sache où elle va et qui aurait des professeurs de qualité ; et ça, je pense que le gouvernement de Toronto, on [le] lui fait penser de temps en temps.

\section{"Dans l'esprit du collège du Sacré-Cour"}

Est-ce qu'elle serait en continuité avec mon travail ? Ça c'est douteux. Mais qu'elle soit en continuité avec le travail du collège du Sacré-Cœur qui a œuvré pendant plus de cinquante ans et qui a conservé, jusqu'à une certaine façon, au moins de la fierté à plusieurs Canadiens français. Je pense que ça ne sortirait pas de moi, mais ça sortirait plutôt de l'esprit du vieux collège du Sacré-Cœur, où on a insisté tellement pour conserver, pour qu'on parle français, au moins je dirais dans les quarante-cinq premières années, parce que plusieurs me disent que, les dernières années, il y avait une faiblesse de ce côté-là. En tous les cas, ça serait dans l'esprit du collège du Sacré-Cœur ; les jésuites ont fait certainement de gros sacrifices pour maintenir le collège du Sacré-Cœur et pour inculquer le plus de français possible dans le cœur et l'âme des Franco-Ontariens. Je pense que ça serait la continuation du collège du Sacré-Cœur plutôt que la continuation du Centre de folklore franco-ontarien. 


\section{"Notre université... on l'aura certainement"}

Je me rappelle de l'article de L'Orignal déchaîné où on disait que les missionnaires démissionnaient ${ }^{61}$. Les jésuites ont été missionnaires dans l'Ontario, missionnaires au point de vue religieux, missionnaires au point de vue de francisation. Moi, je mettrais un bémol à ça : je ne dirais pas que ce sont les jésuites qui ont démissionné, mais ce seraient quelques jésuites qui ont démissionné. Espérons que ce soient des gens qui n'aient pas trop d'autorité pour imposer leur « démissionnage », mais qu'il leur reste encore assez de fierté pour encourager ceux qui veulent continuer l'enseignement du français, que ce soit dans un collège, que ce soit dans une université. Il y a un espoir : le collège Boréal, je ne sais pas encore ce qu'il va donner, il vient de s'ouvrir ${ }^{62}$; j'ai même un de mes petits neveux, arrière-neveu, qui est parti de Montréal pour venir ici au collège Boréal. Et, entre l'université francophone, française qu'on ouvrira dans sept, huit, dix ans, je pense que le collège Boréal a son rôle à jouer et, ça, ça serait d'autant plus merveilleux qu'il n'y a pas de jésuites là-dedans. Ce seraient des gens qui ont pris ailleurs que chez les jésuites, ou peutêtre chez les jésuites, en dehors de la province, qui pousseraient,

61. Yolande Jimenez, « Les missionnaires démissionnent. La Sulfo demande à l'Université de Sudbury de créer l'Université franco-ontarienne », L'Orignal déchaîné, vol. 3, n 3 [4], mercredi 25 octobre1989, p. 1 ; exceptionnellement, le soustitre « journal des étudiants et étudiantes francophones de l'Université Laurentienne », inchangé depuis sa création en septembre 1987, a été remplacé pour ce numéro par « le journal des étudiants et étudiantes de l'Université de l'Ontario français »; source : archive.org/details/LorignalDechaineVol.3No.3 (consultée le 24 août 2015). Voir aussi, dans un numéro subséquent, la réaction de Gabriel Lalemant, "Trois petits tours et puis s'en vont... La question de l'université française déchire les jésuites "», L'Orignal déchaîné, vol. 3, n ${ }^{\circ} 6$, mardi 19 décembre 1989, p. 2. Cet article se présente comme la lettre d'un jésuite à la retraite encourageant les étudiants dans leur lutte pour l'obtention d'une université française en Ontario ; source : archive.org/details/ LorignalDechaineVol.3No.6 (consultée le 24 août 2015). Voir la mise en contexte des enjeux dans Lucien Pelletier, « Les Jésuites de Sudbury vers 1960 : une mutation difficile », Revue du Nouvel-Ontario, $\mathrm{n}^{\circ} 37,2012$, p. 13-81.

62. Créé en juillet 1993 comme « collège de langue française dans le Nord de l'Ontario », le collège Boréal ouvrait officiellement ses portes en septembre 1995, quelques semaines avant le début de cette série d'entrevues. À part son établissement principal à Sudbury, le collège Boréal dispose de six satellites et de trente-cinq points d'accès à ses services en Ontario. Source : www.collegeboreal.ca (consultée le 24 août 2015). 
qui tâcheraient de développer l'esprit français dans ce collège-là en attendant notre université qui viendra quand je serai mort. Même si c'est dans vingt-cinq ans, on l'aura certainement.

\section{ÉPILOGUE : LES PARADOXES D'UN PRÊTRE COLLECTEUR}

Les travaux de l'ethnologue polygraphe Germain Lemieux sont bien connus. Ils se composent d'abord et avant tout d'anthologies de contes - dont la célèbre série Les vieux m'ont conté en 33 tomes $^{63}$ - et de chansons ${ }^{64}$; on relève aussi trois études sur le conte - sa thèse de doctorat Placide-Eustache ${ }^{65}$, un préambule méthodologique à sa monumentale anthologie ${ }^{66}$ et une analyse sur la vigueur de la tradition orale ${ }^{67}$ - avec encore une introduction à son répertoire de chansons ${ }^{68}$; de même, on note deux ouvrages pédagogiques, soit un guide pratique pour la construction d'un four à pain ${ }^{69}$ et un manuel scolaire décrivant le patrimoine matériel de la fin du $\mathrm{XIX}^{\mathrm{e}}$ siècle $^{70}$, sans oublier quelques adaptations populaires de ses contes ${ }^{71}$ et chansons ${ }^{72}$. Au total, treize titres

63. Les vieux m'ont conté, Montréal, Bellarmin, et Paris, Maisonneuve et Larose, 1973-1993, 33 tomes.

64. Chansonnier franco-ontarien I et II, Sudbury, La Société historique du Nouvel-Ontario [SHNo], « Documents historiques » 64, 1974, [4]-138 p., et « Documents historiques » 66, 1975, [4]-142 p.

65. Placide-Eustache : sources et parallèles du conte-type 938, Québec, PuL, «Archives de folklore»10, 1970, vIII-214 p.

66. Les Jongleurs du billochet : conteurs et contes franco-ontariens, Sudbury, SHNo, « Documents historiques » 61-62-63, Paris, Maisonneuve et Larose, et Montréal, Bellarmin, 1972, $134 \mathrm{p}$.

67. De Sumer au Canada français sur les ailes de la tradition, Sudbury, SHNo, « Documents historiques » 51-52, 1968, 73 p.

68. Chanteurs franco-ontariens et leurs chansons, Sudbury, SHNO, «Documents historiques » 44-45, 1963-1964, $113 \mathrm{p}$. $58 \mathrm{p}$.

69. Le Four de glaise, Sudbury, Prise de parole, et Laval, Éditions FM, 1981,

70. La Vie paysanne 1860-1900, Sudbury, Prise de parole, et Laval, Éditions FM, 1982, 239 p.

71. Contes populaires franco-ontariens [I] et II, Sudbury, Shno, « Documents historiques » 25, 1953, 40 p., et « Documents historiques » 35, 1958, 60 p.; Contes de mon pays, Montréal, Héritage, « Katimavik », [1978], c1976, 159 p. ; Les vieux m 'ont conté, Montréal, Bellarmin, et Laval, Éditions FM, 1981, 2 tomes.

72. Folklore franco-ontarien : chansons I et II, Sudbury, SHNo, « Documents historiques » 17, 1949, 48 p., et « Documents historiques » 20,1950, 48 p. ; Les vieux 
distribués en cinquante et un livres et brochures et publiés de 1949 à 1993, soit durant quarante-cinq ans.

La carrière de folkloriste du père Lemieux, commencée en 1948 sous le patronage de la Société historique du NouvelOntario, aura été remarquée tant au Canada qu'à l'étranger et la valeur de sa production ethnologique, principalement la collection Les vieux m'ont conté, consacrée par plusieurs grands prix et distinctions, notamment des doctorats honorifiques décernés par trois universités ontariennes ${ }^{73}$, et par un colloque international autour de son œuvre ${ }^{74}$.

En août 2001, au terme d'un séjour de soixante ans à Sudbury, le père Germain Lemieux quittait ses fonctions de directeur de la recherche au Centre franco-ontarien de folklore et prenait sa véritable retraite à la maison des jésuites à Saint-Jérôme au Québec. C'est là qu'il est mort le 26 mars 2008 à l'âge de quatrevingt-quatorze ans.

Pour bien cerner les buts et les motivations du projet de Germain Lemieux, son rapport à la culture populaire et la valeur de ses travaux pour l'avancement des connaissances, nous avons eu recours, en plus de ses nombreux écrits, aux entretiens autobiographiques qu'il nous a accordés en 1994 et en 1995, dont nous venons de livrer la substance, soit une quinzaine d'heures d'enregistrement ${ }^{75}$.

$$
* * *
$$

Toute sa vie, Germain Lemieux aura recherché un équilibre entre des conjonctures en apparence paradoxales, liées à son origine m'ont chanté, Laval, Éditions FM, 1986, 3 tomes.

73. L'Université York (1977), l'Université d'Ottawa (1978) et l'Université Laurentienne (1984).

74. L'Euvre de Germain Lemieux, s.j. Bilan de l'ethnologie en Ontario français. Actes du colloque tenu à l'Université de Sudbury les 31 octobre, $1^{\text {er }}$ et 2 novembre 1991, sous la direction de Jean-Pierre Pichette, Sudbury, Prise de parole et Centre franco-ontarien de folklore, 1993, $529 \mathrm{p}$.

75. Un premier entretien de $2 \mathrm{~h}$ en date du 23 novembre 1994 a été résumé dans le magazine Continuité et une série de 10 entretiens réalisés entre le 6 novembre et le 11 décembre 1995, 12h 30, a été diffusée à la radio de Radio-Canada à Sudbury et à Montréal. La transcription de ces enregistrements, réalisée par Denise SavardPichette, forme la base de ce " Germain Lemieux par lui-même ». 
sociale et à son appartenance culturelle, à sa vocation religieuse et à son orientation professionnelle, à son tempérament et à ses ambitions personnelles.

\section{Origines paysannes et formation classique}

Germain Lemieux n'a jamais fait mystère de ses origines paysannes. Fils de cultivateurs tant du côté maternel que paternel, il appartenait à une maisonnée nombreuse : il était le neuvième ${ }^{76}$ d'une famille de douze enfants qui, avec les parents, les grandsparents et l'arrière-grand-mère, comptait dix-sept personnes. Ses succès scolaires le destinent au cours classique, ce qui le conduit au Séminaire de Gaspé, à deux cents kilomètres de Cap-Chat. À douze ans, c'est pour lui la première séparation de sa famille avec laquelle il ne vivra plus désormais que durant les vacances d'été. Il apprendra très tôt que la culture populaire dans laquelle son enfance avait baigné ne peut cohabiter avec le programme d'enseignement qu'on dispense dans un collège classique et qui vise d'abord à l'instruction de la relève de l'élite religieuse et de l'élite laïque ; d'où l'accent mis sur le latin, le grec et les institutions de l'Antiquité, avec l'histoire, la littérature et les sciences, sans oublier la philosophie thomiste dans un environnement catholique bien étanche.

Le jeune Lemieux se plaît dans ce milieu, il apprécie le dévouement et la compétence de ses professeurs. S'il considère ce petit collège de soixante-six élèves comme sa seconde famille, il y découvre toutefois le clivage entre la ville et la campagne, moins par « les petites chicanes en récréation » avec les quelques élèves de Montréal ou de Québec, que par l'insensibilité de certains professeurs, « des gens qui venaient de la ville et [qui] n'avaient pas eu connaissance beaucoup de ce qui se passait à la campagne », à l'égard de la tradition orale. « [... D]ès qu'on voulait glisser quelque chose de tradition orale, [...] c'était mal vu », comme il l'expérimenta par le sujet de composition libre

76. Camille Perron, « Contes et paroles de l'Ontario français. La harpe à Ti-Jean ", dans Jean-Pierre Pichette [dir.], L'Euvre de Germain Lemieux, op. cit., p. 40 : «Dans les onze enfants, le neuvième, c'était un petit gars $[\ldots]$ ». 
où il avait raconté le sauvetage d'un pêcheur imprudent, un fait dont il avait été témoin, et qu'on avait mal noté. Néanmoins, l'encouragement d'un autre professeur, qui avait lu et apprécié son récit, l'avait rassuré et lui avait donné le goût de continuer. Car le jeune Lemieux était orgueilleux : « je me rappelle que [...] je voulais être premier $[\ldots]$ même à la petite école $[\ldots]$; quand j'étais troisième, c'était une humiliation extraordinaire "

Garçon timide, il apprendra à parler en public en rhétorique avec l'aide du père Lorenzo Cadieux et s'inscrira à la chorale. Dans ses années de philosophie, son professeur de chimie, le père Boileau, l'avait « frappé par sa facilité de lire de la musique »à première vue, ce qui l'incita à vouloir faire de même. Encouragé par ce résultat, il confie :

[...] ça faisait tellement longtemps que je chantais à l'oreille que dans trois, quatre jours, je suis passé à travers une bonne partie de la musique guidonienne, grégorienne, $[\ldots]$ et puis ça m'a préparé de loin à être folkloriste, pour enquêter dans la chanson et être capable de rédiger ma musique assez facilement.

Il appréciait la pédagogie des jésuites où le raisonnement était favorisé de même que l'efficacité de la répétition, le « rabâchage » comme il disait.

En 1934, l'année du $400^{\circledR}$ anniversaire de l'arrivée de Jacques Cartier à Gaspé, il participe à un concours dont le prix est une bourse d'étude de cinq ans en océanographie. Germain Lemieux, qui est passionné par la mer, la remporte. Mais la perspective de concilier des études scientifiques et la vie religieuse le décide à entrer chez les jésuites et à refuser la bourse.

Après un retrait provisoire de sa famille naturelle, qui dura les sept années de ses études classiques à Gaspé, l'entrée dans sa famille religieuse pour sa formation théologique à Montréal rendait le détachement permanent; elle promettait de le détourner complètement de ses racines gaspésiennes pour s'adonner à son tour à la culture de l'élite. 


\section{Le pédagogue : le folklore au secours des humanités}

Il a vingt-sept ans quand il arrive en Ontario en 1941 pour son premier stage d'enseignement. Son penchant pour la musique et la vie rurale allait le servir...

De 1941 à 1944, je me suis servi du folklore, [...] je suis retourné à mes vieux souvenirs, mes vieux contes, mes vieilles chansons. [...] Et un point me frappait : comment se fait-il que Ti-Jean Poilu, ou le Géant Brigandin, fasse les mêmes choses qu'Hercule ? Je faisais part de cette constatation à mes élèves. [...] Je constatais un fait : dès que je leur racontais un petit bout de conte, $[. .$.$] la classe avait l'air plus intéressante que de suivre$ un manuel. Alors je m'étais dit : «si je pouvais commencer à recueillir des faits ou des contes, ou des légendes, ça pourrait m'aider à renouveler un peu l'enseignement asséchant de ces institutions grecques et latines. L'étudiant me suivrait peut-être davantage et il en apprendrait beaucoup plus ». [...] c'était tellement plat, tellement mourant le cours que le père nous donnait là-bas à Gaspé que je me suis dit : il ne faut pas que je fasse la même chose, la même bêtise. Faudrait qu'il y ait quelque chose de renouvelé.

Et c'est pour ça qu'en 1947, quand je suis revenu, j'avais le même programme, je me suis dit : " Faut que j'aille enregistrer ». J'avais dit au père Cadieux : « Faut voir si nos gens sont bien français ici, dans notre milieu. Est-ce qu'il n'y aurait pas moyen de tenter une enquête pour voir s'ils chantent encore des chansons françaises ? Puis, s'ils chantent encore, s'ils content encore des contes, pour moi, ils sont français ». Alors c'est comme ça que la Société historique a pu me patronner. $[\ldots]$ et $[\ldots]$ que je me suis lancé dans l'enquête à partir de 1948 [...].

Sa motivation initiale était donc avant tout d'ordre didactique. En effet, elle résultait d'une préoccupation personnelle de ce professeur du collège du Sacré-Cœur de Sudbury qui avait d'abord découvert des correspondances entre les récits de la mythologie grecque qu'il enseignait et les contes populaires qu'il avait entendus dans son enfance à Cap-Chat en Gaspésie. Il chercha constamment à sensibiliser ses élèves à la présence de ces mythes 
dans leur culture et plus tard ses étudiants lors de son passage à 1'Université de Sudbury en $1958^{77}$.

Cette intention pédagogique, que Germain Lemieux ne perdra jamais de vue, explique la plus grande partie de son œuvre, tant ses articles de vulgarisation que son œuvre maîtresse. S'il peut s'aligner sur la pédagogie des jésuites, simplifiée à l'extrême quand il la qualifie de rabâchage, ce procédé relève d'abord de l'initiative personnelle du maître qui invente sa voie pour captiver ses élèves. Ce faisant, il actualise une matière aride, en apparence bien loin de leurs préoccupations, il en favorise ainsi l'apprentissage et, en quelque sorte, prend une douce revanche sur cet enseignant qui l'avait puissamment ennuyé durant ses études classiques. Par un curieux retour des choses, la culture antique, véhiculée par les auteurs grecs et latins au programme, le replongeait au cœur de la tradition orale qui avait enchanté son enfance. Plus que la science intellectuelle dispensée pendant ses études classiques et sa formation jésuite, c'est l'empreinte du savoir familial et populaire qui devait marquer la suite de sa vie. Son confrère jésuite, André Girouard, a bien reconnu aussi l'« influence décisive » de son enfance quand il écrit : «Le père Lemieux découvre sa vocation de folkloriste, non pas chez les jésuites, mais chez lui, à sept, huit, neuf ans, assis par terre, en compagnie de ses frères et sœurs, à se faire raconter les aventures de Ti-Jean, les légendes traditionnelles apportées de France. ${ }^{78} \gg$ Ainsi, son origine rurale coïnciderait finalement avec

77. Germain Lemieux, «La Sauvegarde du patrimoine oral», dans René Dionne (dir.), Propos sur la littérature outaouaise et franco-ontarienne, II, Ottawa, la Société des écrivains canadiens, octobre 1979, p. 90 : « Un premier stage d'enseignement à Sudbury entre 1941 et 1945 me permit de constater que les étudiants aimaient encore les contes. Pour mieux fixer dans leur mémoire les nombreuses tâches d'Hercule, je leur racontais un extrait de récit paysan où Jean de l'Ours ramenait sous son bras le dragon à sept têtes ; l'éducation de Jean Poilu n'était pas si différente de celle d'Héraclès. Notre Ti-Jean canadien nettoyait aussi rapidement les étables du roi que Héraclès, les écuries d'Augias. J'en avais la certitude, notre folklore pouvait jouer un grand rôle dans un certain renouveau pédagogique. D'ailleurs, selon quelques hypothèses sérieuses, le conte primitif n'avait-il pas un but pédagogique ? Que l'on songe à l'Iliade et à l'Odyssée dans l'éducation des jeunes Grecs ! »

78. André Girouard, op. cit., p. 138. 
la vocation choisie et fonderait l'œuvre savante qu'il allait édifier en l'abordant sous l'angle de la pédagogie.

C'est pourquoi on peut supposer que la conjoncture, plus que le discernement de ses supérieurs jésuites, avait certainement contribué à l'insertion du jeune professeur Lemieux dans un milieu où sa vocation pourrait éclore. L'enseignement des institutions grecques et latines se faisant précisément dans la classe de versification, on l'avait par conséquent nommé au niveau idéal, les classes inférieures étant réservées à la grammaire et les classes supérieures consacrées à la littérature et à la philosophie ${ }^{79}$. De plus, des huit collèges des jésuites canadiens, établis de Gaspé à Edmonton, Sudbury était le seul qui posséderait une société d'histoire régionale ; la Société historique du Nouvel-Ontario (SHNO) fut d'ailleurs fondée en mars 1942, quelques mois à peine après son installation à Sudbury, par son ancien professeur du Séminaire de Gaspé, Lorenzo Cadieux. La complicité de ce dernier favorisera la mise en place de son entreprise et la diffusion de ses travaux ; sa bibliographie montre bien que cette société fut le banc d'essai de son grand œuvre : entre 1949 et 1974, Lemieux y publie six titres, distribués en neuf livres et brochures de la série « Documents historiques ».

En plus d'introduire des récits traditionnels dans ses cours afin de renouveler l'enseignement des humanités et d'attacher les garçons turbulents de sa chorale, c'est encore par souci pédagogique qu'il accumule dans un petit musée des outils anciens et des maquettes pour illustrer les techniques paysannes de son cours de civilisation canadienne-française ; qu'il sonde les campagnes de l'Ontario, sous couleur d'évaluer la survivance de l'esprit français, et recueille les chansons de tradition orale qui enrichissent d'exemples concrets ses cours sur le Moyen Âge ${ }^{80}$; qu'il imagine aussi toutes sortes de subterfuges pour augmenter

79. Ibid., p. 142 : « Les jeux du hasard».

80. Premières publications de G. Lemieux sur la chanson, inspirées du Romancero du Canada de Marius Barbeau : "C'est tout un flot de sociologie médiévale qui s'est cristal[1]isé en ce genre folklorique. » (Chansonnier francoontarien, [I], 1974, p. 15). 
sa documentation orale et améliorer ses outils d'enquête : fabrication et multiple tirage d'un même voilier pour se procurer un magnétophone à ruban, indexation des publications de la Société d'histoire du père Cadieux pour défrayer l'achat d'une automobile, etc.

\section{3. Études universitaires d'un autodidacte}

\section{Projet d'université à Sudbury}

Depuis le milieu des années 1940, les jésuites désiraient fonder une université à Sudbury. Suivant l'avis qu'un aîné lui avait donné et qui lui avait toujours réussi, Germain Lemieux cherchait à « devancer le rythme du violon ». Une rencontre avec Luc Lacourcière en 1950, qui avait louangé sa première brochure, parue anonymement peu auparavant en 1949 et contenant une vingtaine de chansons, et la visite que ce dernier fit à Sudbury en 1952 allaient inciter Lemieux à entreprendre des études supérieures à l'Université Laval en vue d'obtenir les diplômes requis pour enseigner au niveau universitaire. Il réussit alors à convaincre ses supérieurs de l'envoyer à Québec pour se perfectionner. Contrairement à ce que l'on croit, Lemieux ne va pas à Laval d'abord pour étudier l'ethnologie, mais plutôt dans le but tout pratique de se qualifier pour enseigner les lettres, particulièrement l'histoire, dans l'institution universitaire qu'on va créer. Il a alors presque quarante ans et sait bien ce qu'il veut. Il se fait soustraire les cours généraux de français et autres qu'on destine aux étudiants étrangers, où on l'a bêtement placé au départ. On l'inscrira bientôt dans un programme de licence qui, avec la préparation d'une thèse, le mènera à la maîtrise et au doctorat (entre 1953 et 1961). C'est dans ce contexte qu'il passera du côté du folklore en suivant les cours de Félix-Antoine Savard et de Luc Lacourcière, et qu'il découvrira l'intérêt d'enregistrer le conte dont il utilise déjà des extraits oraux dans son enseignement.

\section{Le petit livre rouge}

Le choix du sujet auquel Germain Lemieux devait consacrer ses 
travaux de maîtrise et de doctorat revient fort probablement à la finesse de son directeur de thèse qui avait la réputation d'assigner à chacun de ses étudiants un thème adapté à sa situation personnelle. Le fait est certainement avéré ici : Luc Lacourcière attribua à un religieux l'étude du roi Eustache ou du général Placide, un conte hagiographique dérivé de la légende de saint Eustache, sachant que le candidat avait lui-même recueilli la moitié des huit versions canadiennes connues et que ce récit était alors oblitéré dans la tradition orale en France ${ }^{81}$. La possible influence de l'écrit sur l'oral méritait une attention particulière dans ce cas, d'autant que des informateurs lui avaient signalé au cours de ses recherches l'existence d'un petit livre rouge racontant cette histoire. On conviendra sans peine que cette piste réclamait de toute nécessité une démarche urgente. Mais la façon dont le chercheur évoque cet épisode révèle un trait de caractère que l'enthousiasme du néophyte ne peut seul expliquer : une étonnante naïveté. Sa demande aux bibliothécaires pourrait faire sourire : « Je cherche un volume qui traite d'Eustache; c'était un petit volume à peu près d'une centaine de pages puis il avait une couverture rouge. » D'ailleurs, il avoue : «Alors, on riait de moi. » En effet, s'il n'avait recherché qu'un « petit livre rouge » d'une centaine de pages, la réaction des bibliothécaires se comprendrait aisément. Pourtant, sa description donnait déjà le titre de l'ouvrage - Eustache ${ }^{82}$ - et les outils de consultation des grandes bibliothèques de l'époque, qui, même avant l'arrivée des fichiers électroniques, classaient les livres au moins par le titre et l'auteur, permettaient de retrouver un ouvrage par son titre seul, sans en connaître l'auteur. Ses insuccès répétés commandent de nouveaux essais, non plus auprès des spécialistes du livre, mais auprès des gens ordinaires : un entrepreneur en démolition, rencontré par hasard dans un tramway à Québec,

81. Germain Lemieux, Placide-Eustache : sources et parallèles du conte-type 938, op. cit., p. 1 : « À la suggestion de M. Luc Lacourcière, notre professeur de folklore à l'université Laval de Québec, nous avons orienté nos travaux vers ce contetype, à cause de son antiquité et de la rareté de ses versions françaises. »

82. Eustache. Épisode des premiers temps du christianisme, traduit de l'allemand de Christophe Schmid par Louis Friedel, Montréal, Librairie Beauchemin, [1917], $108 \mathrm{p}$. 
découvre par miracle dans les débris d'une vieille maison une " petite guenille rouge », soit le livre recherché, qu'il expédiera sans délai à Sudbury après avoir téléphoné de nuit au chercheur qui apprendra enfin le nom de son auteur, Christophe Schmid ; et une élève d'un pensionnat de l'Ouest, " la plus haïssable » de la bande, qui lui procure l'exemplaire qu'elle a déniché dans le galetas où elle avait plus tôt purgé sa punition. Sans mettre en doute la véracité des faits, on croit entendre les exploits de Ti-Jean tant les hasards surprennent et le récit voisine la fabulation.

\section{Confrontations sur des questions de méthode}

Si le père Lemieux a reconnu sans détour qu'il avait fait « la découverte du conte folklorique à l'école de M. Lacourcière », dont il se disait « un fervent disciple», comme il admettait devoir aussi « une partie de [s]a vocation de folkloriste à Marius Barbeau, dans le domaine de la chanson ${ }^{83} »$, il se montre plus critique à l'égard de ses maîtres en entrevue.

À propos de Marius Barbeau, dont il avait tant admiré le Romancero du Canada paru en 1937 et qu'il eut comme professeur vers 1954, il montera en épingle un accrochage bref, sans conséquence, mais épique, survenu à propos de méthode d'enquête. On sait que Germain Lemieux se piquait d'avoir appris la musique par passion en quelques jours et d'avoir mis au point une méthode de sténographie musicale. Or, en posant un jour une question à Barbeau, il ne manque pas de signaler sa méthode :

«Monsieur Barbeau, [...] pour écrire en sténographie une telle chanson qu'un informateur me chante, j'ai besoin de savoir dans quel mode. - Père, il m'a dit, la sténographie n'existe pas ». J'ai dit : « Je vous demande pardon, ça fait au moins sept ans que je l'utilise pour écrire la courbe musicale, la mélodie du commencement de la chanson à côté du titre de ma chanson ». Il dit : « Je veux vous voir après le cours ».

83. Germain Lemieux, «Témoignage de reconnaissance d'un fervent disciple de Luc Lacourcière ", dans Jean-Claude Dupont (dir.), Mélanges en l'honneur de Luc Lacourcière. Folklore français d'Amérique, [Montréal], Leméac, 1978, (p. 39-42), p. 41. 
Bien entendu, Lemieux réussit à sténographier puis à rechanter facilement une mélopée amérindienne que Barbeau lui avait proposée. Des explications suivent et Barbeau se déclare satisfait. L'incident n'aura pas de conséquence.

De même, à une question posée pour mesurer ce qu'il avait retenu des excursions qu'organisait Luc Lacourcière chez des conteurs dans le cadre de ses cours, il répond: « Je ne dirais pas que j'ai appris beaucoup ; j'y suis allé une fois pour dire que j'avais suivi le cours d'enquête avec le maître. » Puis il explique que son expérience du terrain et son système de numérotation des enregistrements, qui était supérieur à celui qu'on lui enseignait, l'avaient amené à conclure : « pratiquement parlant, j'avais peutêtre de l'avance sur monsieur Lacourcière » et « $\mathrm{j}$ 'ai continué quand même ma technique ${ }^{84} \gg$.

Il s'était également fabriqué un système de référence pour indexer ses contes et ses chansons, et il n'accepta jamais ni le catalogue des contes d'Aarne et Thompson ${ }^{85}$, adapté par Luc Lacourcière - même s'il mentionne régulièrement dans Les vieux $m$ 'ont conté les cotes de ce système et les analyses préparées par celui-ci ${ }^{86}-$, ni le catalogue que créa son confrère d'étude Conrad Laforte pour la chanson folklorique de langue française ${ }^{87}$ avec qui il avait eu un différend à propos de la précision de sa codification.

84. Le témoignage de Conrad Laforte qui participa aussi à une expérience contemporaine et similaire fut tout autre : « Luc Lacourcière, $\mathrm{M}^{\mathrm{gr}}$ Savard et Marius Barbeau sont les chercheurs qui m'ont le plus inspiré pour mes travaux de terrain. Je les ai bien connus. J'ai travaillé avec eux. J'ai commencé à faire des recherches avec Lacourcière, dans Bellechasse, auprès du vieux Cléophas Fradette. On y allait toutes les semaines puis, lui, il nous attendait pour conter ses contes. Ça m'a appris un peu à voir comment on manœuvrait dans une enquête. » Voir Jean-Pierre Pichette, "L'air ne fait pas la chanson. Une entrevue avec Conrad Laforte ", dans Rabaska, $\mathrm{n}^{\circ}$ 1, 2003, p. 96.

85. Quatrième édition en 2004 sous la direction de Hans-Jörg Uther, The Types of International Folktales, op. cit.

86. Germain Lemieux, LVMOC, op. cit., tome I, p. 18 : «Dans l'intérêt des folkloristes, nous ajoutons une brève analyse du type du conte d'après l'index international Aarne et Thompson. " Voir aussi, tome II et suivants, à la fin des " Remerciements » : " à M. Luc Lacourcière, directeur des Archives de folklore de l'Université Laval, qui a bien voulu analyser nos contes d'après la classification Aarne-Thompson. »

87. Conrad Laforte, Le Catalogue de la chanson folklorique française, op. cit. 
Il est significatif à ce propos que le trente-troisième volume de la série Les vieux m'ont conté, qui est consacré aux index, ne reprenne pas l'index des types, celui qui est le plus important pour les chercheurs ${ }^{88}$.

Lorsque Luc Lacourcière vint recevoir un doctorat honoris causa de l'Université Laurentienne, il en profita pour remettre sa toge universitaire au père Lemieux, son disciple. Ce fut un honneur très apprécié et un événement hautement médiatisé. Deux ans plus tard, Germain Lemieux ne daigna pas même se rendre à Québec pour recevoir la Médaille Luc-Lacourcière (1979), que lui avaient méritée ses volumes 12 et 13 de la série Les vieux $m$ 'ont conté, sous prétexte qu'il n'avait « plus d'amis ${ }^{89}$ » à Laval ; pourtant, du vivant de Luc Lacourcière, c'est lui-même qui procédait à la remise officielle de cette distinction. La médaille lui fut donc expédiée par la poste et le père Lemieux la plaça bien en vue dans un cabinet vitré parmi les autres honneurs et décorations obtenues... ${ }^{90}$

Ses relations avec ses maîtres et ses collègues auront été irrégulières et plutôt distantes. Par exemple, les souvenirs qu'il évoque à propos de ses contemporains tiennent souvent plus de la rumeur que de faits réels. Très anecdotiques, ils sont liés à la lutte pour les rares subventions disponibles par l'entremise du Conseil des arts du Canada fondé en 1957. Ses collègues deviennent alors des concurrents qui sont choyés alors que lui, il ne l'est pas.

Si telle était son attitude à l'égard de ses maîtres et de ses confrères, on ne peut pas dire qu'il se montra ouvert aux idées qui remettaient ses méthodes en question. L'expérience personnelle

88. L'auteur lui avait même offert de le compiler pour lui faciliter la tâche, mais ce fut en vain.

89. Selon Jean-Claude Dupont qui, à titre de directeur du CÉLAT, lui avait téléphoné pour faire les arrangements ; dire reconfirmé le 28 septembre 2011.

90. Selon des contemporains, ce comportement, incompréhensible à première vue, remonterait au temps de l'enseignement qu'il dispensa à l'Université Laval de 1965 à 1969 en remplacement de Luc Lacourcière ; ce stage d'enseignement aurait connu une fin abrupte pour des raisons administratives. Meurtri, il gardera dès lors une distance respectueuse avec cette institution du centre, tant dans ses pompes que dans ses œuvres (enseignement, revues, recherches, etc.), lui qui opérerait désormais strictement en marge. 
de l'auteur en ce qui concerne la transcription des contes est assez éloquente.

On me reprochait, surtout les jeunes du CÉLAT de Laval, que ma transcription était inintelligible ou difficile à lire. Je le savais, mais par contre j'avais l'expérience de gens qui m'ont écrit dès la parution du premier volume et qui m'ont dit qu'ils avaient passé de très belles vacances de Noël dans un camp avec des parents ou des amis [...]. Plusieurs autres dames qui s'occupaient de garderies d'enfants se servaient de ces contes-là et elles s'apercevaient [...], quand elles lisaient le texte syllabique, que les gens trouvaient ça plus drôle et que ça ressemblait plus à leurs conteurs, leur grand-père ou leur grandoncle qui contaient des contes. J'ai dit : " Je vais continuer à le faire, et même si les gens trouvent que c'est inintelligible ».

La parution en 1983 du livre de Gerald Thomas, Les Deux Traditions, le réconforta, lui qui écrivait : « Il est vrai que la transcription du père Lemieux paraît lourde et difficile à lire, mais il a eu le mérite au moins de tenter une transcription authentique. C'est peut-être le meilleur essai depuis la parution en 1937 de l'ouvrage de Joseph-Médard Carrière. » Et Lemieux de commenter : «Alors, à ce moment-là, je n'ai pas hésité, j'ai eu la conscience tranquille. Je me disais qu'il y a des gens plus autorisés que moi et aussi autorisés que des jeunes qui commencent leur carrière ou qui sont encore au niveau universitaire, qui trouvent que c'est difficile à lire. » Dès lors, les critiques, particulièrement celles des « jeunes du CÉLAT de Laval», étaient-elles malvenues et se heurtaient à une fin de non-recevoir. Il en convient luimême : «Je n'admettais pas facilement certaines techniques qui venaient d'ailleurs, soit pour la musique, soit pour les contes ou les légendes. J'avais mes propres idées, [...] et j'étais un peu têtu. » Son caractère, mais surtout ses convictions, fruits de sa formation et de son expérience, le « cramponnaient dans [s]a résistance » : «Comme j'avais étudié énormément l'Antiquité, le Moyen Âge, [...] la musique [...] depuis longtemps, c'est ça qui m'a formé une espèce de carapace assez dure et qui me faisait réagir plus facilement aux attaques que je recevais. » 
La résistance de l'autodidacte aux méthodes et idées nouvelles empêcha-t-elle ce clerc passionné de former une relève ? On pourrait le croire. Au moment où il déclare que l'enquête ne sera bientôt plus possible, en raison de la disparition des porteurs des anciennes traditions orales, et qu'il plaide pour obtenir des organismes subventionnaires un financement adéquat, il ne songe paradoxalement pas à s'adjoindre au moins des collaborateurs, qu'il préparerait afin d'assurer sa succession. Il se révèle même intransigeant à l'endroit de ceux qui souhaitent s'aventurer dans son domaine. À ces jeunes gens enthousiastes - « au moins quatre ou cinq de mes élèves qui voulaient devenir folkloristes »-, il prescrivait de posséder un véritable gagne-pain avant de s'adonner à l'enquête :

«Écoute un peu, mon vieux, avant d'être folkloriste ou d'être ethnologue, trouve-toi donc un gagne-pain, aie donc une profession ou quelque chose qui va te rapporter le déjeuner du lendemain. Si tu te lances dans l'ethnologie ou le folklore, il va te falloir des finances et si tu n'as pas d'expérience, quelle garantie va-t-on avoir pour te donner une subvention?»

Cette prudence excessive, qui visait à éprouver la « vocation de folkloriste » de jeunes laïcs, contribua certes à en décourager plus d'un ; il le reconnaît lui-même : «C'est le conseil que j'ai donné à tous ces jeunes-là. [...] Peut-être que je les ai découragés, mais je trouvais que les encourager et leur dire "vas-y, vas-y, vas-y, vas-y", c'était les engager sur un terrain dangereux. » On sait qu'il avait déjà avancé qu'un laïc n'avait pas la liberté du religieux pour se destiner à l'enquête ; de là, sa chance d'appartenir à l'ordre des jésuites qui lui procurait le soutien indispensable à son travail.

\section{Un missionnaire aux visées nationalistes}

Germain Lemieux considérait avoir été particulièrement favorisé par son affectation à Sudbury en 1941, un milieu « très simple ", « très pauvre », mais égalitaire où régnait l'esprit d'entraide et « un esprit de famille extraordinaire » : 
Ça m'a aidé et je pense que c'est providentiel que les supérieurs m’aient envoyé ici à Sudbury pour ma propre satisfaction, [...] mon développement personnel et ensuite pour les initiatives que j'ai pu prendre ici dans le milieu qui n'était pas surveillé par des gens à triple doctorat. [...] probablement que, si j'étais allé dans un collège huppé, je n'aurais pas été à la hauteur de la situation, [...] et je n'aurais pas pu me lancer comme je me suis lancé ici à Sudbury.

De plus, il retrouvait à Sudbury la même atmosphère qu'à Gaspé, les mêmes problèmes linguistiques et la même résistance de la population française devant ses droits bafoués. Il cite plusieurs anecdotes qui le montrent. Ainsi, cet épisode qu'il date de 19411942 où les élèves du collège du Sacré-Cœur, faisant les frais de la musique durant les assemblées publiques pour les emprunts de la Victoire ${ }^{91}$, décident d'interpréter le chant national des Canadiens français, Ô Canada, qui ne deviendra l'hymne de tous les Canadiens qu'en 1980, au lieu du God save the King attendu par les anglophones. Il évoquera aussi l'embarras que suscita au sein de l'université l'exemple de la présence « du français sur les armoiries d'Angleterre » qu'il choisit dans son cours d'histoire du Moyen Âge en 1963-1964 pour illustrer l'introduction de mots français dans la langue anglaise.

De telles anecdotes aident à mieux comprendre ce que recouvrait l'expression « conserver l'esprit français » que Germain Lemieux employait pour justifier ses premiers sondages auprès des Franco-Ontariens. À une question directe voulant mesurer son intention de «valoriser la culture française des FrancoOntariens », il répondit : " Oui. Sans trop me le dire, sans trop méditer cette pensée-là, c'était latent, derrière mon toupet de ce moment-là ». Germain Lemieux, qui se fit missionnaire de la sauvegarde du patrimoine oral, désirait « aider notre population

91. Encyclopédie canadienne en ligne : «Les emprunts de la Victoire, contractés par le gouvernement canadien, visaient à récolter de l'argent pour financer les dépenses durant les deux guerres mondiales. [...] Du 15 juin 1941 au $1^{\text {er }}$ novembre 1945, on lance successivement neuf emprunts de la Victoire qui rapportent près de 12 milliards de dollars, dont 52 p. 100 sont achetés par des entreprises, le reste des obligations étant acquises par des particuliers. " Source : www.encyclopediecanadienne.ca/fr/ article/emprunts-de-la-victoire (consultée le 20 août 2015). 
canadienne-française » et souhaitait que « que ces contes-là, ces chansons-là, ces légendes p[uiss]ent inspirer nos artistes $\|^{92}$. Vingt ans plus tôt, son discours s'était fait plus explicite quand il écrivait :

Comprenons-nous l'importance, pour nous, Canadiens français, de mieux connaître notre folklore et de nous y cramponner comme à un ponton de sauvetage ? C'est une source de fierté, un bain d'énergie patriotique, un rempart contre l'anglicisation et l'américanisation. [...] On n'apprendra pas à s'exprimer correctement et élégamment en français, si l'on parle constamment une autre langue [...]. C'est encore par le retour constant à notre tradition ancestrale, autrement dit à notre folklore, que nous découvrirons les raisons d'être fiers de notre passé et d'affronter crânement l'avenir. ${ }^{93}$

Son engagement s'inscrivait de fait dans le prolongement de l'action du collège du Sacré-Cœur de Sudbury qui avait été une " place fortifiée du français ». Il prônait même la création d'une université française en Ontario qui serait le lieu idéal d'accueil de sa documentation et qui pourrait «s'en servir pour étudier davantage la langue française, pour intéresser les étudiants», et qui ferait en sorte « que nos contes, que nos chansons, que nos légendes, que nos techniques artisanales servent à la recherche. » Une telle institution, « le rêve de plusieurs » qu'il entrevoyait comme une véritable « bénédiction », serait en continuité directe avec l'œuvre des jésuites qui, durant plus d'un demi-siècle, « ont fait certainement de gros sacrifices pour maintenir le collège du Sacré-Cœur et pour inculquer le plus de français possible dans le cœur et l'âme des Franco-Ontariens. " Il n'hésite pas à déclarer que l'université franço-ontarienne « serait le couronnement de [s]a carrière $\gg{ }^{94}$.

92. Germain Lemieux, Les vieux m'ont conté, op. cit., vol. 1, p. 20 : « Notre but est d'abord, redisons-le, de faire connaître notre littérature orale à un plus grand public, de façon à rejoindre, un jour ou l'autre, un artiste qui se laisse gagner par la poésie de ces récits. Il en résultera un roman, une opérette, un programme radiophonique, une comédie... ou toute autre pièce artistique inspirée par la tradition ancestrale. »

93. Germain Lemieux, Chanteurs franco-ontariens, op. cit., p. 8.

94. Voir plus haut «Dans l'esprit du collège du Sacré-Cœur ». 
Cet aspect de sa motivation, qui révèle sa fibre patriotique, adhère tout aussi naturellement à l'orientation même de son ordre religieux. Selon André Girouard, « Les jésuites canadiensfrançais ont toujours privilégié les valeurs nationalistes, selon lesquelles l'avenir d'une collectivité ne peut s'imaginer que par ses références à un passé toujours exemplaire. ${ }^{95}$ » Et il rappelle, pour confirmer, que ce sont les jésuites qui ont fondé l'ACJC (Association catholique de la jeunesse canadienne-française) en juin $1904^{96}$ et qu'en France « le père Doncœur, s.j. ${ }^{97}$, avec ses scouts routiers, remet en honneur les pèlerinages à Chartres, la cathédrale par excellence du Moyen-Âge », le Moyen-Âge étant alors la période « exemplaire » absolue ${ }^{98}$.

$$
* * *
$$

Au final, le folkloriste et ethnologue Germain Lemieux adopta une démarche originale, toute centrée sur la pédagogie, celle d'un professeur de cours classique. Dans ce milieu, où la recherche n'était pas une tâche indispensable ni une activité valorisée, on trouvait néanmoins ici et là des dilettantes qui se passionnaient pour la musique et les beaux-arts, la langue et l'histoire, les sciences, etc., et y employaient tous leurs loisirs. Ils tiraient leur formation des lectures à leur portée, des collections qu'ils constituaient avec zèle, d'une quête personnelle en somme qui était rarement sanctionnée par des études supérieures. C'étaient de véritables connaisseurs qui se développaient librement, à leur rythme, et à l'écart des modes et des écoles, mais en parallèle de leur charge d'enseignement. Telle nous apparaît en définitive la posture de Germain Lemieux dans le domaine de la tradition

95. André Girouard, op. cit., p. 140-141 : "Les jésuites : un ordre nationaliste ».

96. Yvan Lamonde, Histoire sociale des idées au Québec : 1896-1929, Montréal, Fides, 2004, p. 68-70.

97. Père Paul Doncœur, 1880-1961.

98. On ne s'étonnera pas que la mise en veilleuse de ces valeurs, au moment de la fédération de l'Université de Sudbury à l'Université Laurentienne bilingue, ait provoqué une profonde division au sein de la communauté jésuite de Sudbury. Lucien Pelletier, op. cit., le montre bien à la section « Vers l'Université Laurentienne », p. 3162, notamment, p. 52, par le vote serré des jésuites, sans majorité, du 21 février 1960. 
orale. Son retour sur les bancs de l'Université Laval à quarante ans visait un but tout pratique, celui d'obtenir le diplôme de lettres qui lui permettrait de professer dans la nouvelle Université de Sudbury, et ne provenait pas d'abord du désir de se former en ethnologie. En ce sens, ses diplômes de deuxième et de troisième cycles $^{99}$ témoignent moins d'une formation sous la conduite de ses maîtres que d'une reconnaissance des acquis de l'autodidacte qui possède déjà ses habitudes tirées de son expérience et qui ne voit guère de raison de les abandonner ou même de les modifier. Ses remarques critiques devant les méthodes de terrain et les divers systèmes de classement le prouvent. Il n'en demeure pas moins que ce pédagogue, autodidacte et diplômé, a construit, à partir de la tradition orale recueillie auprès de témoins sans grande instruction - et qu'il entend redonner comme nourriture et vitamine intellectuelle à la jeunesse et à l'élite de son pays une œuvre monumentale qu'il a réalisée à l'université, mais à l'écart des courants et des modes universitaires, mû par le désir de défendre et d'illustrer la culture populaire de ce petit peuple de langue française dans lequel il se reconnaît parce qu'il lui rappelle son milieu d'origine.

99. Grade de maîtrise ès arts pour «Placide-Eustache. Étude comparée du conte-type 938 », une thèse déposée à la Faculté des lettres en mai 1955, et doctorat d'université (français) pour la thèse "Sources et parallèles du conte-type 938 Placide-Eustache », déposée à l'École des gradués [sic] en mars 1961. L'ouvrage sera publié avec une préface de Luc Lacourcière sous le titre Placide-Eustache. Sources et parallèles du conte-type 938, Québec, Pul, "Archives de folklore »10, 1970, VIII-214 p. 